\title{
A Novel Biosorbent, Water-Hyacinth, Uptaking Methylene Blue from Aqueous Solution: Kinetics and Equilibrium Studies
}

\author{
Md. Nasir Uddin, ${ }^{1}$ Md. Tariqul Islam, ${ }^{2}$ and Sreejon Das ${ }^{1}$ \\ ${ }^{1}$ Department of Chemical Engineering, University of Malaya, 50603 Kuala Lumpur, Malaysia \\ ${ }^{2}$ Department of Mechanical Engineering, University of Malaya, 50603 Kuala Lumpur, Malaysia \\ Correspondence should be addressed to Md. Nasir Uddin; nasir_cep01@yahoo.com
}

Received 4 February 2014; Revised 19 March 2014; Accepted 24 March 2014; Published 15 April 2014

Academic Editor: Dmitry Murzin

Copyright (c) $2014 \mathrm{Md}$. Nasir Uddin et al. This is an open access article distributed under the Creative Commons Attribution License, which permits unrestricted use, distribution, and reproduction in any medium, provided the original work is properly cited.

\begin{abstract}
The adsorption of $\mathrm{MB}$ dye from aqueous solution onto $\mathrm{HCl}$ acid treated water-hyacinth $(\mathrm{H}-\mathrm{WH})$ was investigated by carried out batch sorption experiments. The effect of process parameters such as $\mathrm{pH}$, adsorbent dosage, concentrations and contact time, and ionic strength were studied. Adsorption of $\mathrm{MB}$ onto $\mathrm{H}-\mathrm{WH}$ was found highly $\mathrm{pH}$ dependent and ionic strength shows negative impact on MB removal. To predict the biosorption isotherms and to determine the characteristic parameters for process design, Langmuir, Freundlich, Temkin, and Halsey isotherms models were utilized to equilibrium data. The adsorption kinetics was tested for pseudo-first-order (PFO), pseudo-second-order (PSO), intraparticle diffusion (IPD), and Bangham's kinetic models. The Langmuir isotherm model showed the goodness-of-fit among the tested models for equilibrium adsorption of $\mathrm{MB}$ over $\mathrm{H}-\mathrm{WH}$ and indicated the maximum adsorption capacity as $63.30 \mathrm{mg} / \mathrm{g}$. Higher coefficient of determination $\left(R^{2}>0.99\right)$ and better agreement between the qe (experimental) and $q_{e}$ (calculated) values predicted that PSO kinetic model showed the goodness-of-fit for kinetic data along with rate constant $1.66 \times 10^{-3}, 4.42 \times 10^{-3}$, and $3.57 \times 10^{-3} \mathrm{mg} \cdot \mathrm{g}^{-1} \mathrm{~min}^{-1 / 2}$, respectively, for the studied concentration range. At the initial stage of adsorption, the overall rate of dye uptake was found to be dominated by external mass transfer, and afterwards, it is controlled by IPD mechanism.
\end{abstract}

\section{Introduction}

Adsorption is one of the most widely applied techniques for removal of certain classes of chemical pollutants from waters, especially those that are hardly demolished in traditional water-treatment plants [1]. Amongst the various industrial sectors, textile, tannery, and pharmaceutical industries are emitting significant volume of dyes and pigments into wastewater [2]. The adsorption process can be taken as an effective alternative for the pollutants uptake from waste water only when the adsorbent is inexpensive and does not need an additional pretreatment before its application [3].

The extent of pollutants uptake by aquatic plant has been extensively tested [4-6]. Water-hyacinth (WH), an aquatic plant, has received considerable attention because of its potential to remove pollutants, when used as a biological filtration system [7]. Malik [8] pointed out that the WH has tremendous survival capability in the presence of toxic pollutants and hence it should be able to be used effectively in heavy metals removal process, as well as other pollutants from polluted water. Many great efforts have demonstrated that WH can be used to adsorb a cationic dye (methylene blue, MB) [4], phenol [9], cadmium [5], copper [10], uranium (VI) [11], Victoria blue [12], crystal violet [13], and so forth, from aqueous solution.

Low et al. [12] have performed the biosorption of basic dyes (MB and Victoria blue) by $\mathrm{WH}$ roots at different operating conditions including $\mathrm{pH}$, sorbent dosage, contact time, and initial concentrations. They showed that the rate constant for the sorption of methylene blue is controlled by pseudo-first-order ( $\mathrm{PFO}$ ) model while maximum rate constant was found $6.9 \times 10^{-2}$ per $\min$ for $100 \mathrm{mg} / \mathrm{L}$ of initial methylene blue concentration (IMBC). Finally, they pointed out that, with increasing IMBC $(100-500 \mathrm{mg} / \mathrm{L})$, the rate constant for intraparticle diffusion was also increased 
$\left(0.082-1.554 \mathrm{mg} / \mathrm{g} \mathrm{min}^{1 / 2}\right)$ and $\mathrm{WH}$ roots have a great potential as a biosorbent for basic dyes; however, this is less so for acidic dyes. Soni et al. [14] have studied the batch adsorption to remove the $\mathrm{MB}$ from an aqueous solution over WH roots powder at varying operating conditions such as $\mathrm{pH}$, adsorbent dose, initial concentration of dye, and contact time. They have reported that maximum 95\% removal of dye was attained at optimum experimental condition. Experimental equilibrium data were best correlated by both Langmuir and Freundlich isotherms and the maximum dye uptake was found to be $8.04 \mathrm{mg} / \mathrm{g}$. The adsorption kinetic data are adequately fitted to the pseudo-second-order (PSO) kinetic model along with higher regression determination $\left(R^{2}>0.999\right)$ for all ranges of dye concentrations. Likewise, Kanawade and Gaikwad [15] described that the uptaking of $\mathrm{MB}$ from aqueous solution by using $\mathrm{WH}$ as an adsorbent depends on its initial concentration and contact time. They also noticed that adsorption of $\mathrm{MB}$ onto $\mathrm{WH}$ follows Langmuir isotherm model.

Kaur et al. [13] have used WH as a potential adsorbent to remove dye crystal violet $(\mathrm{CV})$ from aqueous solutions under different experimental conditions corroborating that adsorption increases with increase in contact time, adsorbent dose, temperature, and $\mathrm{pH}$. The experimental sorption data showed the goodness-of-fit with PSO model along with higher correlation coefficients $\left(R^{2}>0.999\right)$. A maximum adsorption capacity of $58.1 \mathrm{mg} / \mathrm{g}$ was achieved from experimental equilibrium data which highly fitted with Langmuir model that enables to describe the adsorptive behavior of the dye onto WH charcoal. Uddin et al. [9] have carried out the adsorption of phenol from aqueous solution by $\mathrm{WH}$ ash utilizing PFO and PSO models at varying experimental conditions such as contact time, phenol concentration, adsorbent dosage, and $\mathrm{pH}$. They reported that the kinetic data followed closely the PSO model as compared with PFO model. On the other hand, Bhainsa and D'Souza [11] have conducted the uranium uptake by dried roots of $\mathrm{WH}$ and found that the adsorption was rapid and the $\mathrm{WH}$ could remove $54 \%$ of the initial uranium present within $4 \mathrm{~min}$ of contact time. With increasing initial uranium concentration, the specific metal ion uptake was decreased, while at higher dose of $\mathrm{WH}$, the uptake rate was increased and reached a plateau beyond the concentration of $6 \mathrm{~g} / \mathrm{L}$. The process was favored at $\mathrm{pH}$ 5-6 and was least influenced by temperature.

In this study, the waste $\mathrm{WH}$, after treatment with $\mathrm{HCl}$ acid, was used and evaluated as a possible biosorbent for the removal of a $\mathrm{MB}$ from aqueous solution. The pretreatment of $\mathrm{WH}$ biomass with $\mathrm{HCl}$ acids causes the loss of biomass weight by removing the lignin [16] and increases the surface area of the $\mathrm{WH}$ due to opening of the pore mouth of the $\mathrm{WH}$ adsorbent. The objectives of the present study are to determine the kinetic and equilibrium batch adsorption parameters for $\mathrm{MB}$ removal from aqueous solution and to predict the maximum possible adsorption capacity. The feasibility of $\mathrm{H}-\mathrm{WH}$ use as a potential adsorbent is also studied by using error functions.

\section{Materials and Methods}

2.1. Adsorbent Preparation. Live WH was collected from the local ponds. The collected WH were cleaned thoroughly with water for several times to eliminate earthy matter and all the soil particles followed by boiling in water for $30 \mathrm{~min}$. Live WH consists of 94-95\% water and barely contains 50$60 \mathrm{~g}$ total solid per kilogram [17]. In the present study, the $\mathrm{WH}$ was subjected to washing and chemical treatment with hydrochloric acid $(\mathrm{HCl})$ to remove lignin and soluble compounds. The WH was soaked in $0.1 \mathrm{M} \mathrm{HCl}$ for $20 \mathrm{~min}$ and again washed with distilled water. The $\mathrm{WH}$ was then dried in the oven, setting temperature in the range of $90-100^{\circ} \mathrm{C}$ for 8 hours. The dried WH was ground, and the powder was used as an adsorbent. Particle size of the adsorbent samples used for the experiments was in the range of $0.15 \times 10^{-3}-0.25 \times$ $10^{-3} \mathrm{~m}$.

2.2. Methylene Blue. Methylene blue $\left(\mathrm{C}_{16} \mathrm{H}_{18} \mathrm{~N}_{3} \mathrm{Cl} \cdot 3 \mathrm{H}_{2} \mathrm{O}\right)$ was purchased from Merck and used without further purification. The stock solutions of $\mathrm{MB}$ were prepared in distilled water. All MB solutions used in this study were prepared by weighing and dissolving the required amounts of $\mathrm{MB}$ in distilled water.

2.3. Adsorption Kinetic Experiments. To study the effect of important parameters like $\mathrm{pH}$, adsorbent mass, initial concentrations, and contact time on the adsorptive removal of $\mathrm{MB}$, the kinetic adsorption experiments were carried out. The experimental procedure was as follows: (1) several $200 \times$ $10^{-3} \mathrm{~L} \mathrm{MB}$ solutions of known concentration, amount of the adsorbent $(\mathrm{H}-\mathrm{WH})$, were taken in a $250 \times 10^{-3} \mathrm{~L}$ stopper plastic conical flask at desired pH. (2) The MB solution was then agitated using a flash shaker at $500 \mathrm{osc} / \mathrm{min}$ constant oscillation rate. The temperature was controlled at $27 \pm$ $2^{\circ} \mathrm{C}$ with neutral $\mathrm{pH}$ of 6.9. (3) Samples were withdrawn at time intervals and were centrifuged, and the residual $\mathrm{MB}$ concentration in solution was measured immediately using UV/VIS spectrophotometer (Shimadzu Model UV1601) at wavelength $662 \mathrm{~nm}$. The amount of dye adsorbed was determined from the difference in concentration between samples withdrawn. The stirring was continued until the concentration of $\mathrm{MB}$ was constant. To investigate the effect of $\mathrm{pH}$ on dye removal was carried over a $\mathrm{pH}$ range of 1-11. The $\mathrm{pH}$ of zero point charge $\left(\mathrm{pH}_{\mathrm{pzc}}\right)$ plays an important role in the adsorption process. The $\mathrm{pH}_{\mathrm{pzc}}$ of $\mathrm{WH}$ adsorbent in the aqueous phase was determined by utilizing the titration method with different system $\mathrm{pH}$ values [18]. For this purpose, $50 \mathrm{~mL}$ of a $0.1 \mathrm{M}$ potassium nitrate solution was taken in a $100 \mathrm{~mL}$ Erlenmeyer flask. A $0.1 \mathrm{~g}$ of adsorbent was added to the solution and agitated with a magnetic stirrer. The $\mathrm{pH}$ was then adjusted by the addition of aqueous solutions of $\mathrm{HCl}$ or $\mathrm{NaOH}(0.10 \mathrm{M})$. After half an hour contact time, the final $\mathrm{pH}$ was calculated and plotted against surface charge of the adsorbent. All the experiments were conducted in triplicate, and the average values were recorded.

2.4. Batch Equilibrium Studies. The batch equilibrium studies were carried out by adding $0.25 \mathrm{~g} \mathrm{H}-\mathrm{WH}$ adsorbent to 
$200 \times 10^{-3} \mathrm{~L} \mathrm{MB}$ solutions of different initial concentrations $(50-250 \mathrm{mg} / \mathrm{L})$ in flash shaker and agitating till the equilibrium was reached and uptake of the dye from the aqueous solution at equilibrium state was calculated by using the following equation:

$$
q_{e}=\frac{\left(C_{0}-C_{e}\right) V}{W}
$$

where $q_{e}$ (mg MB/g H-WH adsorbent) is called adsorption capacity and defined as the amount of $\mathrm{MB}$ adsorbed per unit weight of adsorbent $(\mathrm{H}-\mathrm{WH})$ at equilibrium state. $C_{0}$ and $C_{e}(\mathrm{mg} / \mathrm{L})$ are the liquid-phase concentrations of $\mathrm{MB}$ at initial and equilibrium states, respectively. The volume of the solution is $V(\mathrm{~L})$ and $W$ is the mass of dry adsorbent used $(\mathrm{g})$.

2.5. Batch Kinetic Studies. The procedures of kinetic experiments were basically identical to those of equilibrium tests. The effect of adsorbent dosage was investigated by contacting $200 \times 10^{-3} \mathrm{~L}$ dye solution of initial concentration of $100 \mathrm{mg} / \mathrm{L}$ with different $\mathrm{H}-\mathrm{WH}$ adsorbent dosage $(0.5-3 \mathrm{~g} / \mathrm{L})$ till the equilibrium was achieved. Kinetics of adsorption was studied by analyzing adsorptive uptake of the dye from the aqueous solution at different time intervals and the amount of adsorption at time $t, q_{t}$ (mg MB/g H-WH adsorbent), was calculated by using the following equation:

$$
q_{t}=\frac{\left(C_{0}-C_{t}\right) V}{W},
$$

where $C_{0}$ and $C_{t}(\mathrm{mg} / \mathrm{L})$ are the liquid-phase concentrations of $\mathrm{MB}$ at initial and any time, respectively. The volume of the solution is $V(\mathrm{~L})$ and $W$ is the mass of dry adsorbent used $(\mathrm{g})$.

2.6. Fourier Transform Infrared Spectroscopy (FTIR). Fourier transform infrared spectroscopy of the adsorbent was done by using an FTIR spectrophotometer (Model: FTIR 2000, Shimadzu, Kyoto, Japan). Spectra of the samples were recorded in the range from 500 to $4000 \mathrm{~cm}^{-1}$. Approximately $3 \%$ of dry samples were taken to prepare about $150 \mathrm{mg} \mathrm{KBr}$ disks shortly before analysis of the FTIR spectra.

2.7. Effect of Ionic Strength on Adsorption. The effect of ionic strength on the amount of $\mathrm{MB}$ adsorbed by $\mathrm{H}-\mathrm{WH}$ was performed over the $\mathrm{NaCl}$ concentration range from 0 to $0.18 \mathrm{~mol} / \mathrm{L}$. MB solutions of $100 \mathrm{mg} / \mathrm{L}$ were agitated with $0.25 \mathrm{~g} / \mathrm{L}$ of $\mathrm{H}-\mathrm{WH}$ for 4 hours.

\section{Establishment of Adsorption Models}

3.1. Adsorption Isotherm Models. The adsorption isotherm indicates how the adsorption molecules distribute between the liquid phase and the solid phase when the adsorption process reaches an equilibrium state. Langmuir isotherm [19] refers to homogeneous monolayer adsorption onto a surface containing a finite number of adsorption sites of uniform strategies of adsorption with no transmigration of adsorbate in the plane of surface. The linear equation in this model is represented as follows:

$$
\frac{C_{e}}{q_{e}}=\frac{C_{e}}{q_{\max }}+\frac{1}{q_{\max } K_{L}} .
$$

Equation (3) is known as Langmuir isotherm where $q_{e}$ is the amount of adsorbate in the adsorbent at equilibrium $(\mathrm{mg} / \mathrm{g}), C_{e}$ is the equilibrium concentration $(\mathrm{mg} / \mathrm{L})$, and $q_{\max }$ and $K_{L}$ are the Langmuir isotherm constants related to adsorption capacity and rate of adsorption, respectively. The above linearized equation can be fitted to get the maximum capacity, $q_{\max }$, by plotting a graph of $C_{e} / q_{e}$ versus $C_{e}$.

To determine whether the $\mathrm{MB}$ adsorption process by $\mathrm{H}-\mathrm{WH}$ is favorable or unfavorable for the Langmuir type adsorption process, the isotherm shape can be classified by a term $R_{L}$, a dimensionless constant separation factor, which is defined below:

$$
R_{L}=\frac{1}{1+K_{L} C_{0}}
$$

where $R_{L}$ is the dimensionless separation factor and $C_{0}$ is the initial solution concentration $(\mathrm{mg} / \mathrm{L})$. The parameter indicates the shape of the isotherm accordingly: unfavorable (when $R_{L}>1$ ), linear (when $R_{L}=1$ ), favorable (when $0<R_{L}>1$ ), and irreversible (when $R_{L}=0$ ). The calculated $R_{L}$ values at different initial MB concentration are plotted to determine the applicability of Langmuir isotherm.

The Freundlich isotherm [20] model is derived by assuming a heterogeneous surface of adsorption capacity and adsorption intensity with a nonuniform distribution of heat of adsorption. The well-known linearized form of Freundlich isotherm can be written as

$$
\ln q_{e}=\ln K_{f}+\frac{1}{n} \ln C_{e},
$$

where $K_{f}$ and $1 / n$ are Freundlich constants related to adsorption capacity and adsorption intensity, respectively. The $\ln K_{F}$ is equivalent to $\ln q_{e}$ when $C_{e}$ equals unity. However, in other cases when $1 / n \neq 1$, the $K_{F}$ value depends on the units upon which $q_{e}$ and $C_{e}$ are expressed. The $K_{f}\left((\mathrm{mg} / \mathrm{g})(\mathrm{L} / \mathrm{g})^{1 / n}\right)$ represents the quantity of dye adsorbed onto $\mathrm{H}-\mathrm{WH}$ for unit equilibrium concentration. A value for $1 / n$ below one indicates a normal Langmuir isotherm while a value above one represents cooperative adsorption [21]. The plot of $\ln q_{e}$ versus $\ln C_{e}$ gave a straight line and predicts the value for Freundlich constants parameters.

Temkin and Pyzhev [22] pointed out that the heat of adsorption of all the molecules on the adsorbent surface layer would decrease linearly with coverage due to adsorbateadsorbate interactions. They pointed out that the heat of adsorption of all the molecules on the adsorbent surface layer would decrease linearly with coverage due to adsorbateadsorbate interactions. The linear form of this isotherm can be given by

$$
q_{e}=B_{T} \ln C_{e}+B_{T} \ln K_{T} .
$$

In (6), $B_{T}$ and $K_{T}$ are the Temkin isotherm constants. The constant $B_{T}$ is related to the heat of adsorption. A plot of $q_{e}$ 
versus $\ln C_{e}$ enables one to determine the constants $K_{T}$ and $B_{T}$.

The Halsey isotherm model [23] reported the multilayer adsorption and the fitting of the experimental data to this equation explains the heteroporous nature of the adsorbent. The Halsey model can be expressed as follows:

$$
\ln q_{e}=\frac{1}{n_{H}} \ln K_{H}-\frac{1}{n_{H}} \ln C_{e} .
$$

According to (7), a plot of $\ln q_{e}$ versus $\ln C_{e}$ should give a straight line and the Halsey constants which are usually denoted by $n_{H}$ and $K_{H}$ can be determined from the plot.

3.2. Adsorption Kinetic Models. The kinetic behavior of MB removal by using $\mathrm{H}-\mathrm{WH}$ was studied to evaluate the rate of adsorbate uptake from aqueous solution, which controls the mechanism of dye adsorption. Several two-parameter kinetic models, namely, pseudo-first-order (PFO), pseudosecond-order (PSO), and intraparticle diffusion (IPD), are applied to evaluate the dynamics of the adsorption of $\mathrm{MB}$ from aqueous solution onto H-WH. These models can be expressed as follows.

PFO model [24] is

$$
q_{t}=q_{e}\left(1-e^{-K_{1} t}\right)
$$

PSO model [24] is

$$
q_{t}=\frac{q_{e}^{2} K_{2} t}{1+q_{e} K_{2} t}
$$

IPD model [25] is

$$
q_{t}=k_{W M} t^{1 / 2} .
$$

All of these models are widely used to determine the kinetics of adsorption process and convert the equation into a nonlinear form by transforming the kinetics variables. The difference between experimental data and theoretical data can be estimated from the curvature plots with regression coefficient $\left(R^{2}\right)$. Besides the value of $R^{2}$, the suitability of kinetic models to narrate the adsorption process was further analyzed by using several statistical equations which read

normalized standard deviation (NSD)

$$
=100 \times \sqrt{\frac{\sum_{i=1}^{N}\left[\left(q_{e, \exp }-q_{e, \mathrm{cal}}\right) / q_{e, \exp }\right]^{2}}{N-1}},
$$

sum of the errors squared (SSE)

$$
=\sum_{i=1}^{N}\left(q_{e, \exp }-q_{e, \text { cal }}\right)^{2}
$$

Sum of absolute errors (EABS)

$$
=\sum_{i=1}^{N}\left|q_{e, \exp }-q_{e, \mathrm{cal}}\right|_{i} .
$$

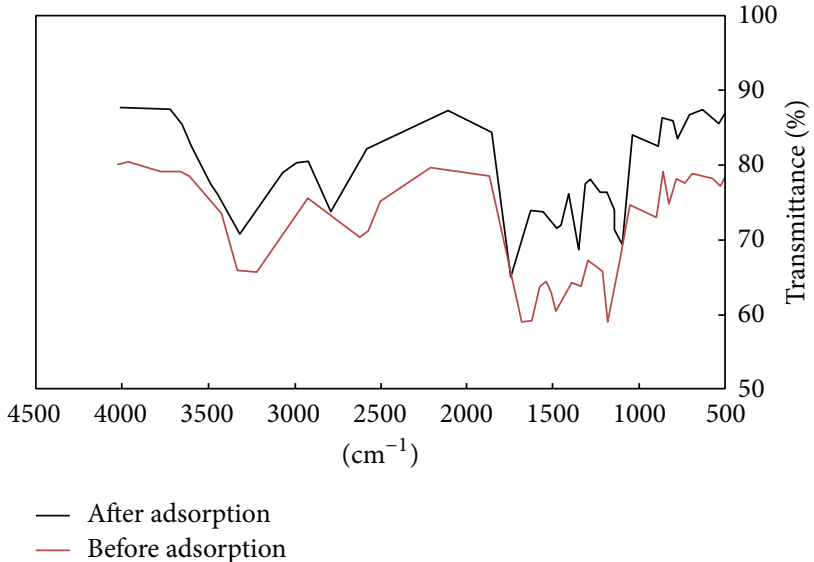

FIGURE 1: FTIR analysis before and after adsorption of MB onto WH.

From (11), the number of data points, experimental adsorption capacities, and calculated adsorption capacities are represented by $N, q_{e, \text { exp }}, q_{e, \text { cal }}$, respectively.

\section{Results and Discussions}

4.1. FTIR Analysis. WH is a natural fiber, which is primarily composed of cellulose, lignin, and wax. The FTIR spectrum of WH would therefore contain many bands at the different absorption regions. The WH FTIR spectrum cannot be accurately interpreted to identify its functional groups. It can, however, be used as one of the tools to differentiate the modified WH. Figure 1 shows a very complicated behavior of $\mathrm{WH}$ during the course of adsorption. Primarily, WH indicates band at $3390 \mathrm{~cm}^{-1}$ due to stretching frequency of $-\mathrm{OH}$. A minor shift was noticed for the spectra results from aromatic ring from 1593 to $1598 \mathrm{~cm}^{-1}$. This is likely because the interaction between carboxylic groups $\left(-\mathrm{COO}^{-}\right)$and $\mathrm{MB}^{+}$cations would be difficult due to proximity between aromatic rings of lignin moieties and $\mathrm{MB}$ The adsorption band for WH in the range between 1312 and $1005 \mathrm{~cm}^{-1}$ was shifted which reflects the stretching frequency of $\mathrm{C}-\mathrm{O}$ of methoxy group $\left(-\mathrm{OCH}_{3}\right)$ of the aromatic ring of lignin. Through the electrostatic interaction, other hydroxyl and carboxyl groups such as phenolic and aliphatic extractives could participate in sorption of MB. Poots et al. [26] showed that carboxylic and hydroxyl groups were identified as the most important groups for sorption of MB. After adsorption, it is seen that the trends of $\mathrm{C}-\mathrm{O}$ were altered from $1036 \mathrm{~cm}^{-1}$ to $1039.60 \mathrm{~cm}^{-1}$ It is obvious from Figure 1 that $\mathrm{MB}$ gave strong spectra at $1580 \mathrm{~cm}^{-1}, 1420 \mathrm{~cm}^{-1}, 1376 \mathrm{~cm}^{-1}$, and $650.70 \mathrm{~cm}^{-1}$, respectively.

4.2. Effect of $p H$ on Adsorption. The interaction between dye molecule and adsorbent is basically a combined result of charges on dye molecules and the surface of the adsorbent [27]. Figure 2 shows that $\mathrm{pH}$ of the solution has significantly affected adsorption of $\mathrm{MB}$ on $\mathrm{H}-\mathrm{WH}$. When the $\mathrm{pH}$ of dye solution was increased from 1.835 to 6.934 , the adsorption capacity of $\mathrm{MB}$ increased from 8.87 to $50.41 \mathrm{mg} / \mathrm{g}$. At $\mathrm{pH}$ 


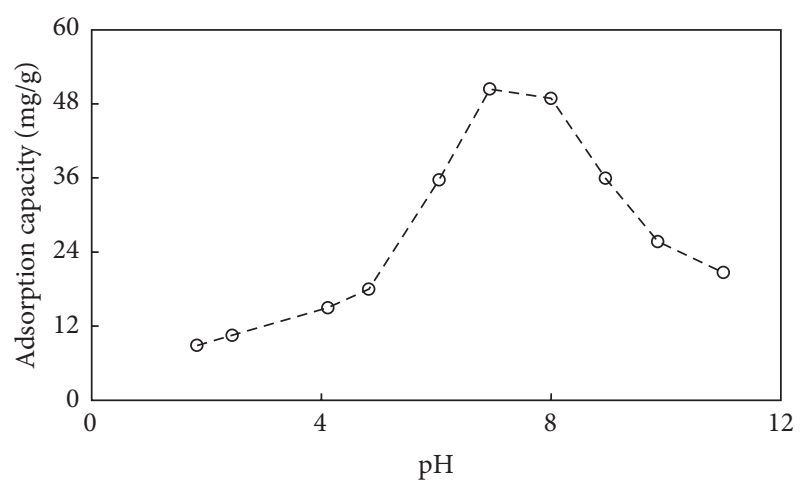

FIgURE 2: Effect of $\mathrm{pH}$ on adsorption capacity for $\mathrm{MB}$ onto $\mathrm{H}-\mathrm{WH}$.

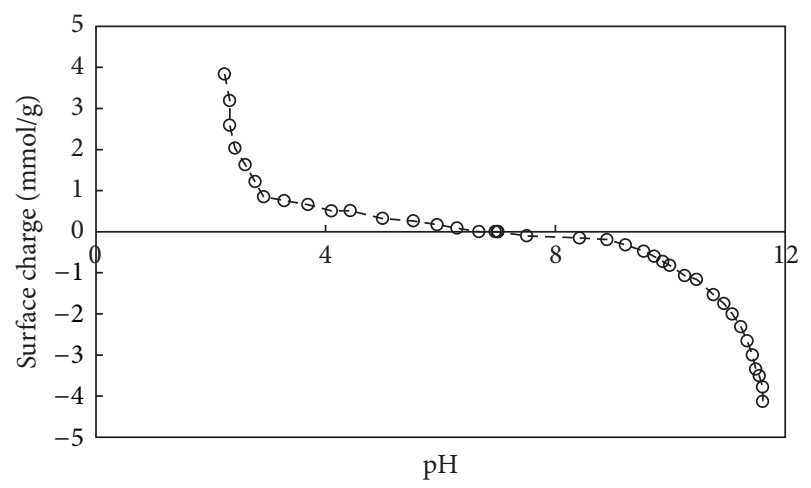

FIGURE 3: Determination of $\mathrm{pH}_{\mathrm{PZC}}$ of $\mathrm{H}-\mathrm{WH}$ adsorbent.

range of 4.827 to 6.934 , the uptake of dye increased very rapidly from 18 to $50.41 \mathrm{mg} / \mathrm{g}$ as shown in Figure 2. The HWH sorbent achieved its optimum adsorption capacity for $\mathrm{MB}$ at $\mathrm{pH}$ of 6.934 . A decrease from 50.41 to $20.67 \mathrm{mg} / \mathrm{g}$ of adsorption capacity was observed in the $\mathrm{pH}$ range of 6.934-11. This fact may be explained from the solubilization of organic groups present on the $\mathrm{H}-\mathrm{WH}$ sorbent [18].

The adsorption of $\mathrm{MB}$ onto adsorbent surface is influenced by the surface charge on the sorbent and the initial $\mathrm{pH}$ of the solution [28]. The $\mathrm{pH}$ at the point of zero charge, $\mathrm{pH}_{\mathrm{pzc}}$ value of $\mathrm{H}-\mathrm{WH}$, was found to be 6.72, which is very close to neutral point (Figure 3). As the $\mathrm{pH}$ of the solution increases (when $\mathrm{pH}>\mathrm{pH}_{\mathrm{pzc}}$ ), the surface of $\mathrm{H}-\mathrm{WH}$ may get negatively charged due to sorption of $\mathrm{OH}^{-}$, and the sorption process is highly favored through electrostatic force of attraction. At $\mathrm{pH}$ 6.934, surface of $\mathrm{H}-\mathrm{WH}$ sorbent was negatively charged to its maximum number. Further addition in $\mathrm{pH}$ did not increase surface charge intensity as well as adsorption capability [29]. On the other hand, when $\mathrm{pH}<$ $\mathrm{pH}_{\mathrm{pzc}}$, the $\mathrm{H}-\mathrm{WH}$ surface may get positively charged due to adsorption of the $\mathrm{H}^{+}$and a force of repulsion occurs between the dye cation and the $\mathrm{H}-\mathrm{WH}$ sorbent surface. At low $\mathrm{pH}(<2)$ sorption was unfavorable, probably because of the excess $\mathrm{H}^{+}$ ions competing for sorption sites on the adsorbent making $\mathrm{H}^{+}$-dye ${ }^{+}$exchange unattractive. Several investigations have reported that $\mathrm{MB}$ adsorption usually increases as the $\mathrm{pH}$ is increased $[3,30]$.

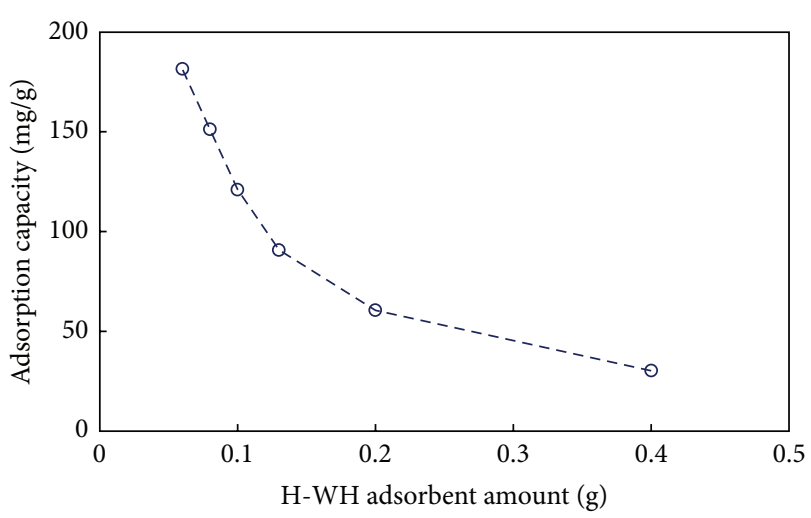

FIGURE 4: Adsorbent dosage function of adsorption capacity for MB over $\mathrm{H}-\mathrm{WH}$ at $\mathrm{pH}$ of 6.9 and $27 \pm 2^{\circ} \mathrm{C}$.

4.3. Effect of Adsorbent Dosage. Adsorbent dose is representing an important parameter due to its strong effect on the capacity of an adsorbent at given initial concentration of adsorbate. Effect of adsorbent dose on removal of $\mathrm{MB}$ was monitored by varying adsorbent doses from 0.50 to $3.0 \mathrm{gm} / \mathrm{L}$. The adsorption of dye decreased with the adsorbent dose and the percentage of dye removal increased (24.20-96.80\%) with increasing $\mathrm{H}-\mathrm{WH}$ adsorbent dosage from 0.50 to $3.0 \mathrm{gm} / \mathrm{L}$ [12]. At higher biomass to solute concentration ratio, there is a very fast superficial sorption onto the adsorbent surface that produces a lower solute concentration in the solution than when biomass to solute concentration ratio is lower. This is because a fixed mass of biomass can only adsorb a certain amount of dye. Therefore, the more the adsorbent dosage is, the larger the volume of effluent that a fixed mass of $\mathrm{H}$ WH can purify is [31]. Figure 4 shows the effect of $\mathrm{H}-\mathrm{WH}$ adsorbent dosage on adsorption capacity. It can be seen that from Figure 4 the adsorption capacity reduced from 181.50 to $30.25 \mathrm{mg} / \mathrm{g}$ when $\mathrm{H}-\mathrm{WH}$ adsorbent dosage increased from 0.50 to $3.0 \mathrm{gm} / \mathrm{L}$. Similar results were reported by Patil et al. [32]. Many factors can be attributed to this adsorbent concentration effect. The most important factor is that adsorption site remains unsaturated during the adsorption reaction. This decrease in adsorption capacity with increase in adsorbent mass is mainly attributed by nonsaturation of the adsorption sites during the adsorption process [33]. Thus, the amount of dye adsorbed onto unit weight of adsorbent gets reduced causing a decrease in equilibrium adsorption capacity, $q_{e}$ $(\mathrm{mg} / \mathrm{g})$, with increasing adsorbent mass.

4.4. Effect of Initial MB Concentration and Contact Time. Figure 5 shows the effect of initial $\mathrm{MB}$ concentration, $\mathrm{C}_{0}$, on the kinetics of adsorption of the dye at $\mathrm{pH}$ (6.9), $\mathrm{H}$ $\mathrm{WH}$ dosage $0.25 \mathrm{~g} / \mathrm{L}$, and $27 \pm 2^{\circ} \mathrm{C}$. It can be apparent from Figure 5 that adsorption capacity increased with increase in $\mathrm{MB}$ concentration. This indicates that the initial dye concentration plays an important role in determining the adsorption capacity of $\mathrm{MB}$ on $\mathrm{H}-\mathrm{WH}$. This may be related to the solution state of $\mathrm{MB}$ at different concentrations. In the beginning of the adsorption process, the MB is adsorbed on the external surface of $\mathrm{H}-\mathrm{WH}$ particle, which increases 


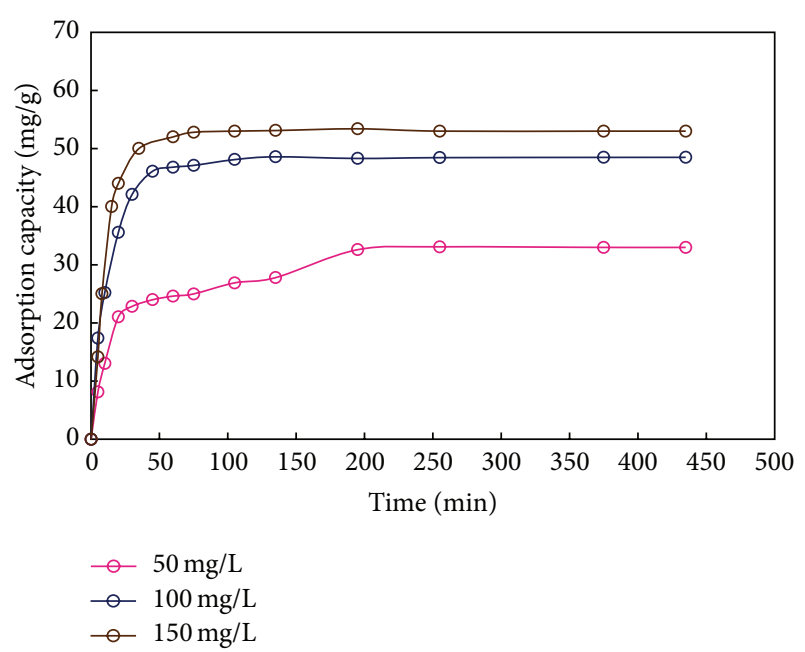

FIGURE 5: Adsorption kinetics of $\mathrm{MB}$ on $\mathrm{H}-\mathrm{WH}$ for different initial concentration at $\mathrm{pH}$ of 6.9 and $27 \pm 2^{\circ} \mathrm{C}$.

the local concentration of $\mathrm{MB}$ on the surface and leads to the formation of MB aggregates. MB molecules are known to form dimers and aggregates, depending on the conditions of solution such as $\mathrm{pH}$, concentration, and presence of other ions [34, 35]. MB aggregates can migrate from the external surface of $\mathrm{H}-\mathrm{WH}$ to the internal pores, resulting in deaggregation of the $\mathrm{MB}$ aggregates and restoring monomers. At high loading rates of $\mathrm{MB}$, it is expected that agglomerates are predominant in solution, while monomers and dimers are virtually absent in the $\mathrm{MB}$-adsorbent complexes on the solid surface. As the $\mathrm{MB}$ concentrations increased from 50 to $150 \mathrm{mg} / \mathrm{L}$, the experimental adsorption capacity for $\mathrm{MB}$ increased from 33 to $53.10 \mathrm{mg} / \mathrm{g}$. It can be inferred from Figure 5 that the contact time needed to reach equilibrium with initial concentration was less than 2 hours. The surface of $\mathrm{H}-\mathrm{WH}$ contains a large number of active sites and $\mathrm{MB}$ uptake can be related to the active sites on equilibrium time [36]. It is also noticed from Figure 5 that more than $80 \%$ of the total amount of dye uptake was observable in the initial rapid phase and thereafter the sorption rate was found to decrease.

4.5. Effect of Ionic Strength. The extent of MB adsorption was sharply attributed by the concentration and nature of the electrolyte ionic species added to the dyebath [37]. The influence of common salt $(\mathrm{NaCl})$ on the $\mathrm{MB}$ adsorption rate over $\mathrm{H}-\mathrm{WH}$ adsorbent is shown in Figure 6. Principally, the adsorption capacity decreases with an increase in ionic strength if electrostatic forces between the adsorbent surface and adsorbate ions are attractive. Likewise, the adsorption capacity increases with an increase in ionic strength if electrostatic interaction is repulsive $[38,39]$. As seen in Figure 6 the adsorption capacity and removal percentage decreased in the presence of salt concentration. This is likely because of a competitive effect between $\mathrm{MB}$ ions and cations from the salt for the sites available for the adsorption process when salt concentration added in the MB solution; that is, the degree of adsorbing reduced as salt concentration increased.

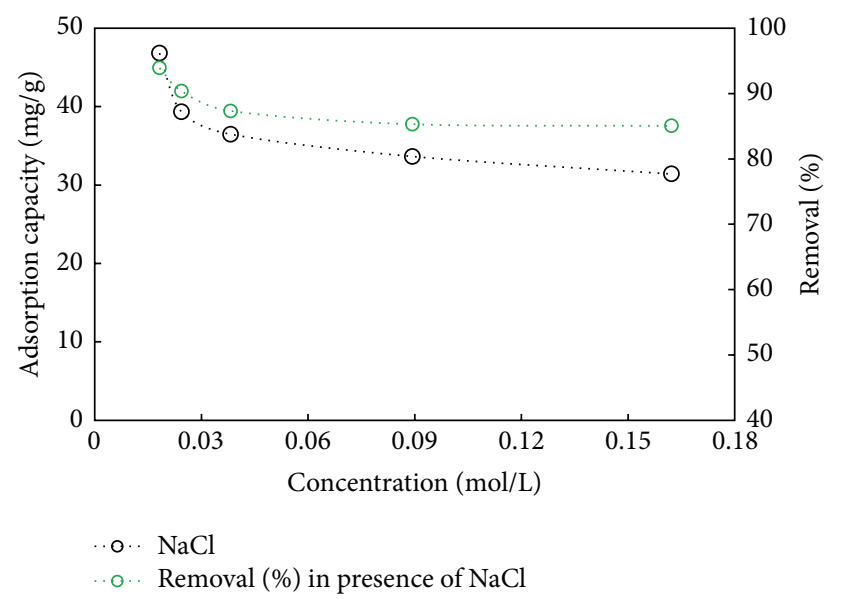

Figure 6: Effect of ionic strength on MB removal over $\mathrm{H}-\mathrm{WH}$ adsorbent.

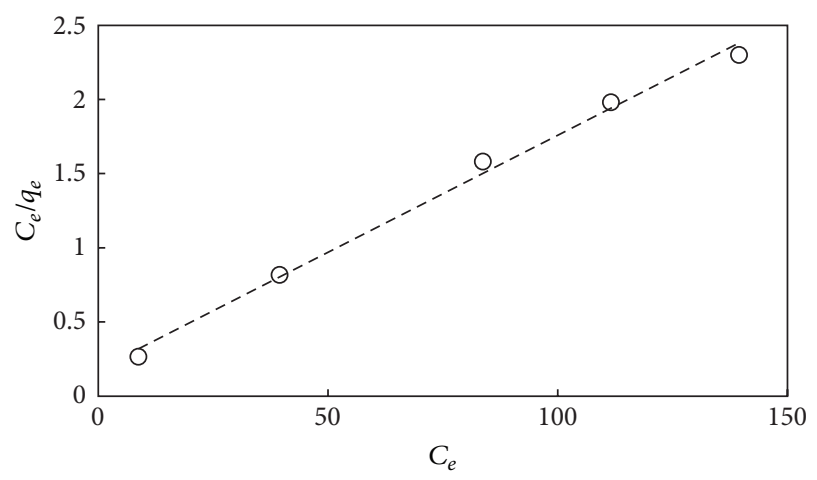

FIGURE 7: Langmuir isotherm model for MB adsorption onto $\mathrm{H}-\mathrm{WH}$ at $\mathrm{pH}$ of 6.9 and $27 \pm 2^{\circ} \mathrm{C}$.

As seen in Figure 6, the dye sorption and removal percentage were decreased in the presence of salt concentrations ( 0 to $0.18 \mathrm{~mol} / \mathrm{L}$ ). The values of adsorption capacity reduced from 46.82 to $31.41 \mathrm{mg} / \mathrm{g}$ while removal percentage reduced from $93.91 \%$ to $85.1 \%$. Moreover, the effective concentration of MB and available reaction sites decrease as the ionic strength increases; therefore, a decreasing characteristic in adsorption capacity of $\mathrm{MB}$ over the adsorbents is highlighted. However, $\mathrm{H}$-WH adsorbent still has larger removal percentage at $0.16 \mathrm{~mol} / \mathrm{L}$ of salt concentration, and hence it could be used to efficiently remove $\mathrm{MB}$ from aqueous solution with higher salt concentration.

4.6. Adsorption Isotherms Studies. The well-established Langmuir isotherm suggests the presence of monolayer coverage of the adsorbate at the outer surface of the adsorbent; once an adsorbate molecule occupies a site, no further adsorption can take place at that site. The linearized equation (3) can be fitted to get the maximum capacity, $q_{\max }$, by plotting a graph of $C_{e} / q_{e}$ versus $C_{e}$ as shown in Figure 7 and it is found to be $63.30 \mathrm{mg} / \mathrm{g}$. The isotherm parameters calculated from the linear relationship of $C_{e} / q_{e}$ versus $C_{e}$ are represented in 
TABLE 1: Parameters and correlation coefficient of the studied isotherm models.

\begin{tabular}{lcc}
\hline Model name & Evaluated parameters & $R^{2}$ \\
\hline $\begin{array}{l}\text { Langmuir } \\
\text { isotherm }\end{array}$ & $q_{\max }=63.30 \mathrm{mg} / \mathrm{g} ; K_{L}=0.0879 \mathrm{~L} / \mathrm{mg}$ & 0.9938 \\
$\begin{array}{l}\text { Freundlich } \\
\text { isotherm }\end{array}$ & $K_{f}=21.22(\mathrm{mg} / \mathrm{g})(\mathrm{L} / \mathrm{mg})^{1 / n} ; n=4.737$ & 0.9851 \\
$\begin{array}{l}\text { Temkin } \\
\text { isotherm }\end{array}$ & $K_{T}=3.823 \mathrm{~L} / \mathrm{mg} ; B_{T}=9.4401$ & 0.9873 \\
$\begin{array}{l}\text { Halsey } \\
\text { isotherm }\end{array}$ & $K_{H}=5.51 \times 10^{-7}(\mathrm{~L} / \mathrm{g}) ; n_{H}=-4.737$ & 0.9851 \\
\hline
\end{tabular}

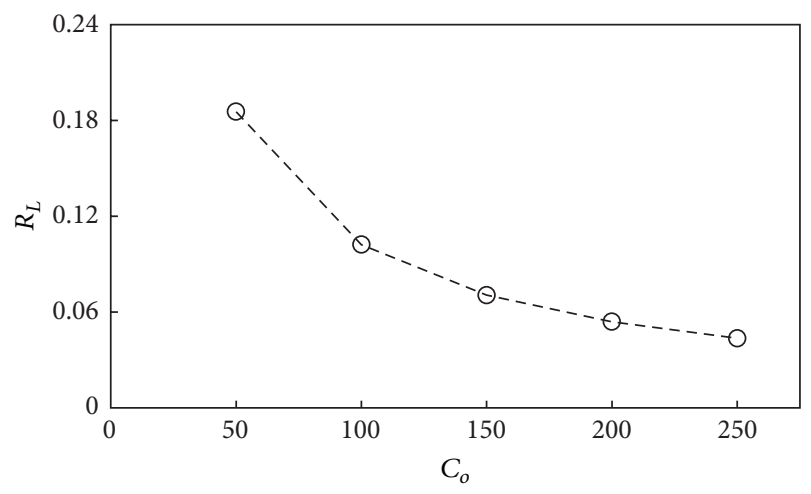

Figure 8: Separation factor for MB onto H-WH.

Table 1. Several factors such as number of sites in the biosorbent material, the accessibility of the sites, the chemical state of the sites (i.e., availability), and the binding strength can be affected by the maximum capacity. The linear regression coefficient $\left(R^{2}\right)$ is good agreement to reach unity $(0.9938)$ for the studied concentrations. The applicability of Langmuir isotherm to describe the $\mathrm{MB}$ adsorption onto $\mathrm{H}-\mathrm{WH}$ surface can be viable from Figure 8 .

From Figure 8 it was observed that sorption was found to be more favorable at higher concentrations. Also the value of $R_{L}$ in the range of 0 to 1 at all initial dye concentrations confirms the favorable uptake of the MB process. Also higher $R_{L}$ values at lower dye concentrations show that the adsorption is more favorable at lower dye concentrations.

According to (5), a plot of $\ln q_{e}$ versus $\ln C_{e}$ gave a straight line (Figure 9) and predicts the value for Freundlich constants parameters. The experimental results of $(1 / n)<1$ indicated that the adsorption isotherms of MB adsorption on H-WH followed normal Langmuir models [40]. Higher value of $K_{f}$ $\left(21.22(\mathrm{mg} / \mathrm{g})(\mathrm{L} / \mathrm{mg})^{1 / n}\right)$ confirms the suitable dye-adsorbent interaction in the studied concentration range. Table 1 gives the values of parameters and correlation coefficient of the Freundlich equation. A lower $R^{2}$ value (0.9851) of Freundlich equation is indicating that the experimental data correlates well with Langmuir isotherm which reflects the monolayer adsorption. This may be explained from the complex nature of the sorbent material and its varied multiple active sites as well as irregular pattern of the experimental results. In

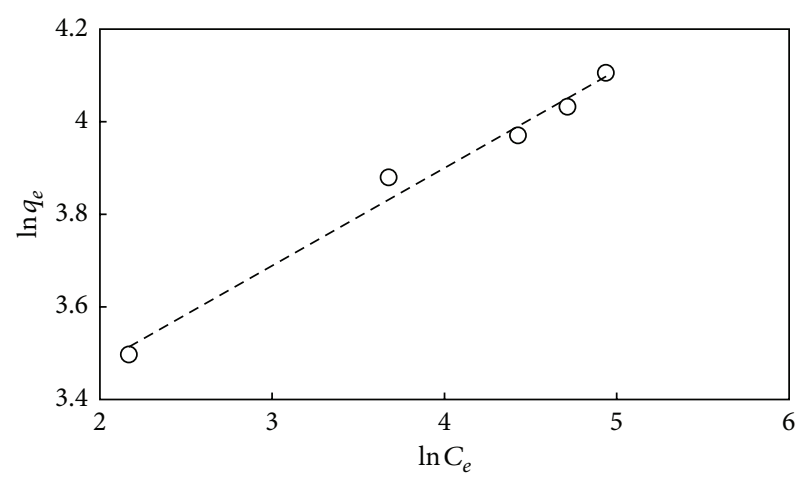

FIGURE 9: Freundlich isotherm model for $\mathrm{MB}$ adsorption onto $\mathrm{H}$ $\mathrm{WH}$ at $\mathrm{pH}$ of 6.9 and $27 \pm 2^{\circ} \mathrm{C}$.

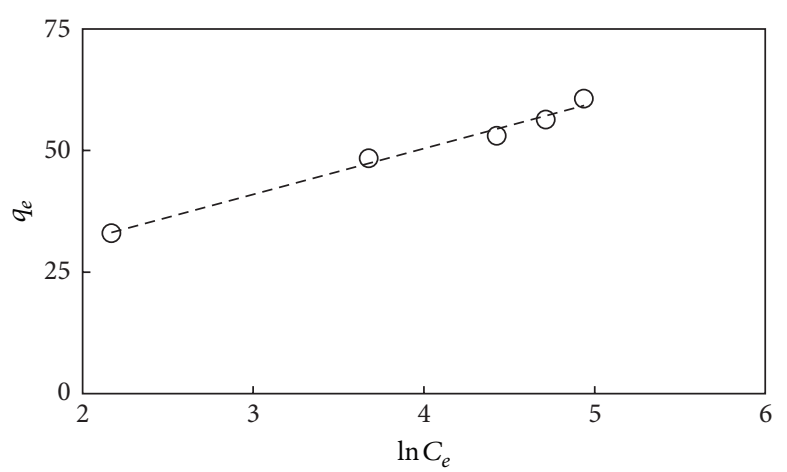

FIgURE 10: Temkin isotherm model for MB adsorption onto $\mathrm{H}-\mathrm{WH}$ at $\mathrm{pH}$ of 6.9 and $27 \pm 2^{\circ} \mathrm{C}$.

addition, the higher value (4.737) of $n$ is also confirming that the interaction between sorbent and solute molecules is expected to be strong.

The experimental equilibrium data for $\mathrm{MB}$ adsorption over H-WH adsorbent, calculated from (1), is fitted with Temkin isotherm (6). A plot of $q_{e}$ versus $\ln C_{e}$ should give a straight line (Figure 10) and enables one to determine the constants $K_{T}$ and $B_{T}$. These constants are represented in Table 1. Higher value (9.4401) of $B_{T}$ indicates the endothermic nature of adsorption process. The value of the correlation coefficient $\left(R^{2}\right)$ confirms that the adsorption of MB dyes onto $\mathrm{H}-\mathrm{WH}$ adsorbent provides better results than that of the Freundlich isotherm but less than that of Langmuir isotherm for the studied concentration range.

The Halsey isotherm model describes the multilayer adsorption and the fitting of the experimental data to this equation validates the heteroporous nature of the adsorbent. According to (7), a plot of $\ln q_{e}$ versus $\ln C_{e}$ should give a straight line (Figure 11) and the Halsey constants which are usually denoted by $n_{H}$ and $K_{H}$ can be determined from the plot. The evaluated parameters are represented in Table 1. Evidently, the regression coefficient values for Halsey and Freundlich isotherm models are similar (0.9851). This is indicative that the correlation of the experimental equilibrium data for $\mathrm{MB}$ removal onto $\mathrm{H}-\mathrm{WH}$ by Halsey model is in good agreement with Freundlich isotherm model. 
TABLE 2: Adsorption rate constant and coefficient of correlation associated with kinetic models.

\begin{tabular}{lcccccccc}
\hline Model name & $C_{0}(\mathrm{mg} / \mathrm{L})$ & $q_{e, \text { exp }}(\mathrm{mg} / \mathrm{g})$ & $q_{e, \text { cal }}(\mathrm{mg} / \mathrm{g})$ & Identified parameters & $R^{2}$ & NSD & SSE & EABS \\
\hline \multirow{3}{*}{ PFO } & 50 & 33.00 & 25.50 & $K_{1}=0.0405 \mathrm{~min}^{-1}$ & 0.8675 & 7.0160 & 2.6508 & 1.1687 \\
& 100 & 48.39 & 21.55 & $K_{1}=0.0760 \mathrm{~min}^{-1}$ & 0.8996 & 4.9911 & 4.0881 & 1.2191 \\
& 150 & 53.10 & 8.131 & $K_{1}=0.03178 \mathrm{~min}^{-1}$ & 0.9073 & 7.9788 & 7.8205 & 2.1378 \\
\hline \multirow{3}{*}{ PSO } & 50 & 33.00 & 34.36 & $K_{2}=0.00166 \mathrm{~g} \cdot \mathrm{mg}^{-1} \mathrm{~min}^{-1}$ & 0.9963 & 2.2246 & 2.6310 & 1.3700 \\
& 100 & 48.39 & 49.26 & $K_{2}=0.00442 \mathrm{~g} \cdot \mathrm{mg}^{-1} \mathrm{~min}^{-1}$ & 0.9996 & 3.2251 & 4.0524 & 1.2670 \\
& 150 & 53.10 & 54.00 & $K_{2}=0.00357 \mathrm{~g} \cdot \mathrm{mg}^{-1} \mathrm{~min}^{-1}$ & 0.9992 & 5.2038 & 4.1585 & 1.3942 \\
\hline \multirow{3}{*}{ IPD } & 50 & 33.00 & $k_{W M}=0.7140 \mathrm{mg} \cdot \mathrm{g}^{-1} \mathrm{~min}^{-1 / 2}$ & 0.9576 & 5.5710 & 7.0520 & 2.8170 \\
& 100 & 48.39 & $k_{W M}=0.1506 \mathrm{mg} \cdot \mathrm{g}^{-1} \mathrm{~min}^{-1 / 2}$ & 0.8366 & 2.7590 & 2.7340 & 6.9580 \\
& 150 & 53.10 & & $k_{W M}=0.1040 \mathrm{mg} \cdot \mathrm{g}^{-1} \mathrm{~min}^{-1 / 2}$ & 0.9376 & 2.390 & 3.4840 & 7.1093 \\
\hline
\end{tabular}

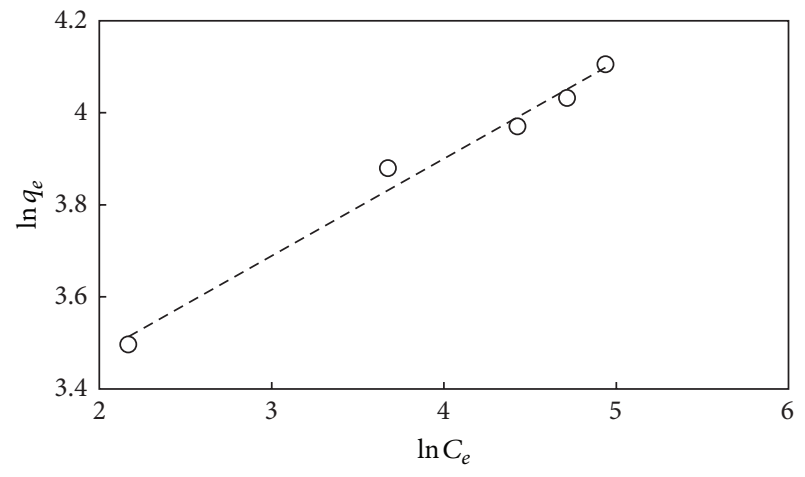

Figure 11: Halsey isotherm model for MB adsorption onto $\mathrm{H}-\mathrm{WH}$ at $\mathrm{pH}$ of 6.9 and $27 \pm 2^{\circ} \mathrm{C}$.

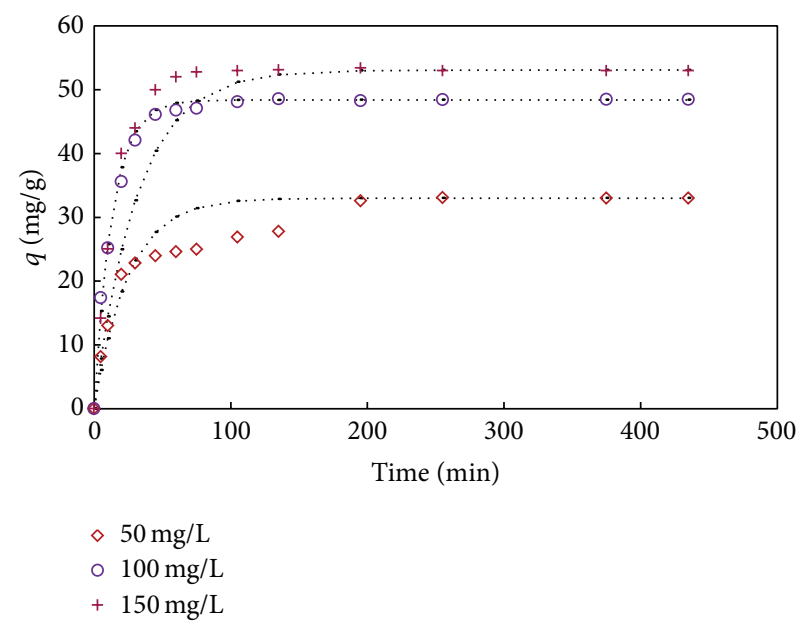

FIGURE 12: The representation of PFO model for MB adsorption on $\mathrm{H}-\mathrm{WH}$ for different initial concentration at $\mathrm{pH}$ of 6.9 and $27 \pm 2^{\circ} \mathrm{C}$.

4.7. Adsorption Kinetics Studies. The experimental kinetic data of MB, calculated from (2), were correlated by three kinetic models as stated above. The calculated parameters of the kinetic equations (8)-(10) with $R^{2}$ values at different IMBCs are presented in Table 2. It may be observed from Figure 12 that, as IMBC was increased, the sorption capacity was found to be increased. The experimentally observed adsorption capacity enhances from 33 to $53.10 \mathrm{mg} / \mathrm{g}$ as the IMBC increases from 50 to $150 \mathrm{mg} / \mathrm{L}$. A possible reason may be that different IMBCs have different solution phases. In the early stage of the sorption process, $\mathrm{MB}$ generates aggregates. This is because the local concentration of $\mathrm{MB}$ onto the $\mathrm{H}$ WH surface enhanced due to $\mathrm{MB}$ uptake was found to be on the external surface of $\mathrm{H}-\mathrm{WH}$ adsorbent. Additionally, it is known that aggregates and dimers are generated from $\mathrm{MB}$ molecules but the formation environment depends on process variables such as $\mathrm{pH}$, the presence of other ions, and concentration $[34,35]$. Moreover, the migration of $\mathrm{MB}$ aggregates from the outer surface of the $\mathrm{H}-\mathrm{WH}$ adsorbent to interior pores leads to the disaggregation of $\mathrm{MB}$ aggregates and release of monomers. It is anticipated that the $\mathrm{H}-\mathrm{WH}$ adsorbent surface was virtually free of both monomers and dimers while agglomerates seem to dominate the dye solution when high concentration loading of $\mathrm{MB}$ was tested.

By analyzing the $R^{2}$ values, it may be seen from Table 2 that the PFO kinetic model was not appropriate for accurately describing the adsorption of $\mathrm{MB}$ onto $\mathrm{H}-\mathrm{WH}$. It can also be observed from Figure 12 that the adsorption data did not show good fit by PFO equation (8) for all IMBCs. This is indicative of the fact that all studied concentrations deflect from theory from the initial stage of adsorption. As the IMBC increases, the difference between experimentally obtained values for adsorption capacity and calculated values from PFO model was increased in a way that the experimentally obtained values are higher than the calculated value. It is also confirmed from Table 2 that, for all studied concentrations, the PFO model shows a poor fit to the experimental data because the difference between experimental and calculated adsorptions is much higher.

The experimental kinetic data of $\mathrm{MB}$ were further validated by using PSO model of (9). In comparison to Figure 12, Figure 13 showed that the PSO model fits the experimental data better for the whole period of adsorption. It is also proved from Table 2 that the PSO model better represented the adsorption kinetics and there is good agreement between experimental and calculated adsorption capacity values. In comparison to PFO, the PSO model shows less NSD (values from 2.2246 to 5.2038), SSE (values from 2.6310 to 4.1585 ), and EABS (values from 1.3700 to 1.3942 ) values for all studied concentrations. It is meant to that the calculated value obtained from PSO model are closer to 
TABLE 3: Adsorption kinetic behavior in the PSO model and equilibrium approaching factor $\left(R_{w}\right)$.

\begin{tabular}{lcc}
\hline$R_{w}$ value & Type of kinetic curve & Approaching equilibrium level \\
\hline$R_{w}=1$ & Linear & Not approaching equilibrium \\
$1>R_{w}>0.1$ & Slightly curved & Approaching equilibrium \\
$0.1>R_{w}>0.01$ & Largely curved & Well approaching equilibrium \\
$R_{w}<0.01$ & Pseudorectangular & Drastically approaching equilibrium \\
\hline
\end{tabular}

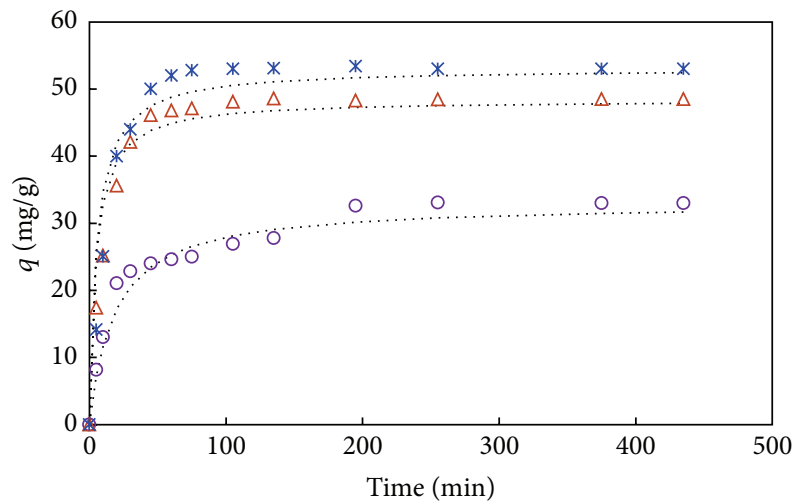

$$
\begin{aligned}
& \circ 50 \mathrm{mg} / \mathrm{L} \\
& \Delta 100 \mathrm{mg} / \mathrm{L} \\
& * 150 \mathrm{mg} / \mathrm{L}
\end{aligned}
$$

FIGURE 13: The representation of PSO model for MB adsorption on $\mathrm{H}-\mathrm{WH}$ for different initial concentration at $\mathrm{pH}$ of 6.9 and $27 \pm 2^{\circ} \mathrm{C}$.

the experimental results than the calculated value obtained from PFO model.

It may be observed from Table 2 that the PSO reaction rate model adequately explains the kinetics of $\mathrm{MB}$ dye adsorption with a high correlation coefficient for all ranges of dye concentrations studied. Comparing the $R^{2}$ values for each studied concentration, it is observed from Table 2 that the PSO model provides the best fit with higher $R^{2}$ values (0.9963 to 0.9992) in comparison to the PFO model $\left(R^{2}\right.$ values from 0.8675 to 0.9073 ). This result suggests that, as the initial MB concentration increases (50-150 mg/L), the sorption capacity responds positively. As IMBC increases from 50 to $100 \mathrm{mg} / \mathrm{L}$, the PSO rate constant, $K_{2}$, increases from $1.66 \times 10^{-3}$ to $4.42 \times 10^{-3} \mathrm{~g} \cdot \mathrm{mg}^{-1} \mathrm{~min}^{-1}$; however, with further increase in IMBC to $150 \mathrm{mg} / \mathrm{L}$, the $K_{2}$ shows opposite trends and decreases to $3.57 \times 10^{-1} \mathrm{~g} \cdot \mathrm{mg}^{-1} \mathrm{~min}^{-1}$. A possible reason may be that different initial $\mathrm{MB}$ concentrations have different solution phases. In the early stage of the sorption process, $\mathrm{MB}$ generates aggregates. This is because the local concentration of $\mathrm{MB}$ onto the $\mathrm{H}-\mathrm{WH}$ surface is enhanced due to the contaminant uptake occurring on the external surfaces of the adsorbent. The higher $R^{2}$ values indicate that chemical reaction is the rate controlling step throughout the sorption process.

For a PSO type adsorption process it is necessary to investigate the kinetic curve's characteristics by means of an approaching equilibrium factor value in order to determine

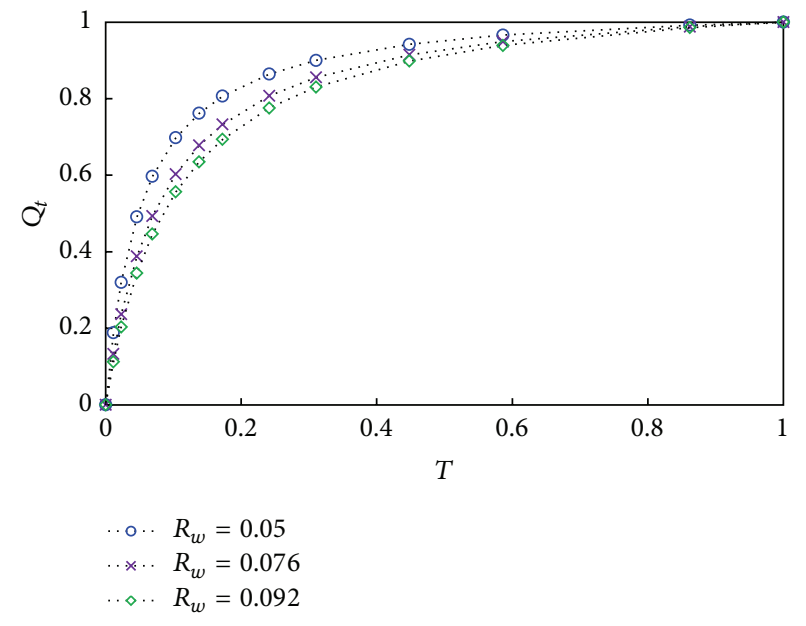

FIGURE 14: Characteristic curves of PSO kinetic model.

whether the MB adsorption by $\mathrm{H}-\mathrm{WH}$ approaches equilibrium or not. The approaching equilibrium factor can be written as displayed in the following equations [41]:

$$
\begin{gathered}
K_{2} q_{e} t_{\text {ref }}=\frac{R_{w}-1}{R_{w}}, \\
Q_{t}=\frac{T}{R_{w}(1-T)+T},
\end{gathered}
$$

where $T=t / t_{\text {ref }}, R_{w}$ is known as an approaching equilibrium factor, $t_{\text {ref }}$ is the longest operating time in an adsorption system, and $Q_{t}$ is a dimensionless factor, respectively. A plot of $Q_{t}$ versus $T$ should give a curvature for three values of $R_{w}$ as shown in Figure 14. The approaching equilibrium values for the PSO kinetic model are in Table 3.

The curvature of the adsorption curve decreases as $R_{w}$ increases. It may be clearly noticed from Figure 14 that the curvature of the adsorption process increases when $R_{w}=0.05$ while it decreases at a higher value of $R_{w}$ (i.e., 0.092). This may be attributed to the fact that the removal of $\mathrm{MB}$ from aqueous solution requires larger amounts of the H-WH adsorbent [41]. It may be also apparent from Figure 14 that the characteristic adsorption curve approaches pseudoequilibrium in the range $0.1>R_{w}>0.01$ and this finding is consistent with the literature $[42,43]$. The relationship between the operating time for the adsorption of $\mathrm{MB}$ by $\mathrm{H}-\mathrm{WH}$ and the extent of its adsorption is represented by this characteristic curve. Such results are very important for effective engineering design under practical scenarios. 


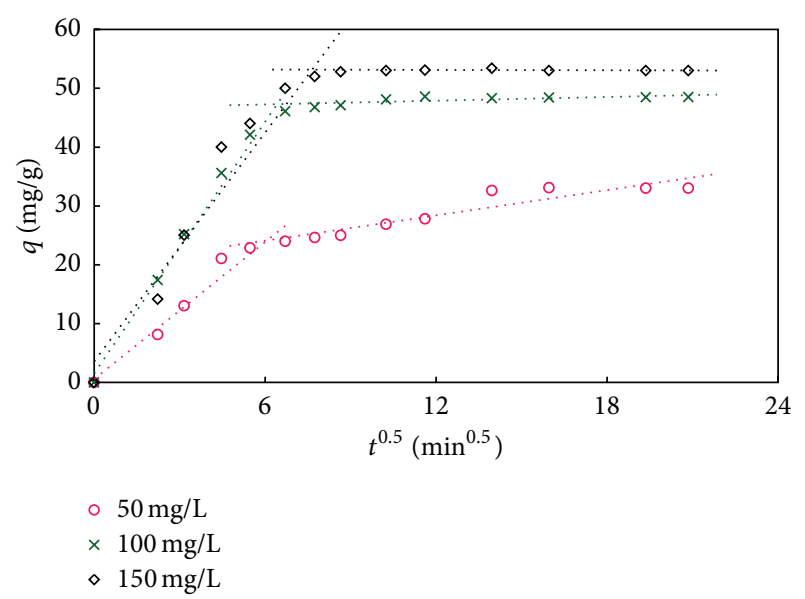

FIGURE 15: Representation of IPD kinetic model for MB adsorption on $\mathrm{H}$-WH for different initial concentration at $\mathrm{pH}$ of 6.9 and $27 \pm 2^{\circ} \mathrm{C}$.

Intraparticle diffusion (IPD) equation was used to study diffusion mechanism. Broadly speaking, the initial adsorption usually occurs on the adsorbent surface during batch experiments. Additionally, there is a high probability of the adsorbate to diffuse into the interior pores of the adsorbent and, hence, IPD emerges as the dominant process [44]. According to Weber and Morris [44] a plot of solute sorbed against the square root of the contact time should yield a straight line passing through the origin when the ratelimiting step is IPD controlled.

Thus the $k_{\mathrm{WM}}\left(\mathrm{mg} / \mathrm{g} \mathrm{min}^{1 / 2}\right)$ value can be obtained from the slope of the plot of $q(\mathrm{mg} / \mathrm{g})$ versus $t^{0.5}\left(\mathrm{~min}^{1 / 2}\right)$. Theoretically, Figure 15 shows the plot of $q$ versus $t^{0.5}$ for methylene blue onto H-WH particles. From Figure 15, it was observed that the sorption process tends to be followed by two phases. The two phases in the intraparticle diffusion plot suggest that the sorption process proceeds by surface sorption and intraparticle diffusion. The first incisive stage of the plot indicates a boundary layer effect while the second linear stage is due to intraparticle or pore diffusion. The slope of the second linear stage of the plot has been defined as the intraparticle diffusion parameter $k_{\mathrm{WM}}\left(\mathrm{mg} / \mathrm{g} \mathrm{min}^{1 / 2}\right)$ while intercept is proportional to the boundary layer thickness. It is indicative of the fact that the larger the intercept value is, the greater the boundary layer effect is and, therefore, the greater the contribution of the surface sorption to the rate-limiting step is. The calculated intraparticle diffusion coefficient $k_{\mathrm{WM}}$ value was given by $0.7140,0.1506$, and $0.1040 \mathrm{mg} / \mathrm{g} \cdot \mathrm{min}^{1 / 2}$ for an IMBC of 50,100, and $150 \mathrm{mg} / \mathrm{L}$. It is also noted that the value of the intercept increases from 19.827 to 53.243 as the IMBC increases from 50 to $150 \mathrm{mg} / \mathrm{L}$. The $R^{2}$ values (Table 2) for this model were lower compared to PSO model and show higher deviation between experimental and calculated values (higher NSD, SSE, and EABS values than those of PSO model).

As the double nature of intraparticle diffusion plot confirms the presence of both film and pore diffusion, in order to predict the actual slow step involved, the kinetic data

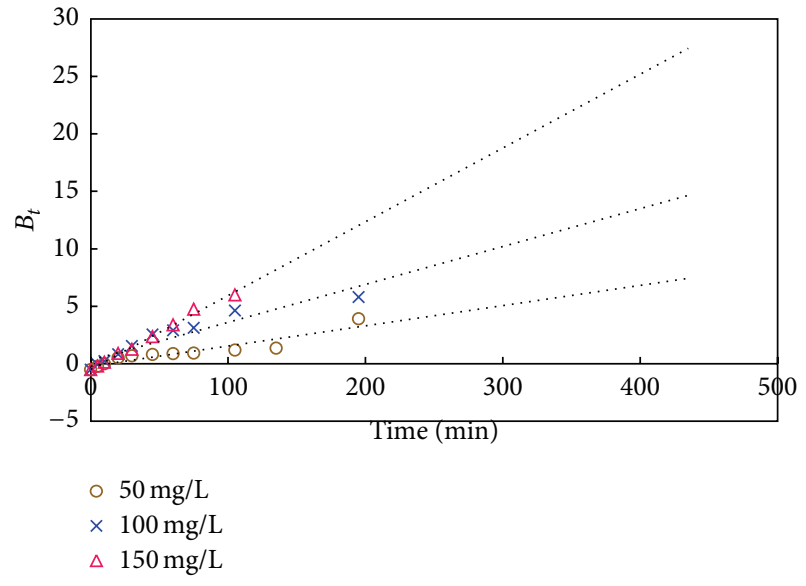

FIGURE 16: Representation of Boyd plots for MB adsorption on $\mathrm{H}-$ $\mathrm{WH}$ for different initial concentration at $\mathrm{pH}$ of 6.9 and $27 \pm 2^{\circ} \mathrm{C}$.

were further analyzed using the Boyd kinetic expression. This kinetic expression predicts the actual slowest step involved in the sorption process for different sorbent-sorbate systems. The linearized Boyd kinetic expression is given by [4]

$$
B_{t}=-0.4977-\ln (1-F) \text {, }
$$

where $F=q_{t} / q_{e}$ is the fractional attainment of equilibrium at time $t$ and $B_{t}$ is a mathematical function of $F$. The $B_{t}$ values at different contact times can be calculated using (13). The calculated $B_{t}$ values were plotted against time $t$ as shown in Figure 16. Figure 16 is used to identify whether external transport or intraparticle transport controls the rate of sorption [4]. From Figure 16, it was observed that the plots were linear but do not pass through the origin, confirming that, for the studied initial dye concentration, external mass transport mainly governs the sorption process [4]. The calculated $B$ values were used to calculate the effective diffusion coefficient, $D_{i}\left(\mathrm{~m}^{2} / \mathrm{s}\right)$, using the relationship

$$
B=\frac{\pi^{2} D_{i}}{r^{2}},
$$

where $r$ represents the radius of the particle calculated by sieve analysis and by assuming spherical particles. The $D_{i}$ values were found to be $8.78 \times 10^{-10}, 0.2 \times 10^{-9}$, and $20 \times$ $10^{-10} \mathrm{~m}^{2} / \mathrm{s}$ for an IMBC of 50,100 , and $150 \mathrm{mg} / \mathrm{L}$, respectively.

To correlate the experimental findings evidently, sorption data were further utilized to identify the slow step occurring in the present adsorption system based on the equation proposed by Aharoni et al. [45]:

$$
\ln \ln \left(\frac{C_{0}}{C_{0}-q_{t} m}\right)=\ln \left(\frac{k_{o} m}{2.303 V}\right)+\alpha \ln t .
$$

As such linear plot of $\ln \ln \left(C_{0} / C_{0}-q_{t} m\right)$ versus $\ln t$ (Figure 17) should give the explanation about the diffusion of adsorbate into pores of adsorbents is not the only ratecontrolling step [46]. The film and pore diffusion both were 


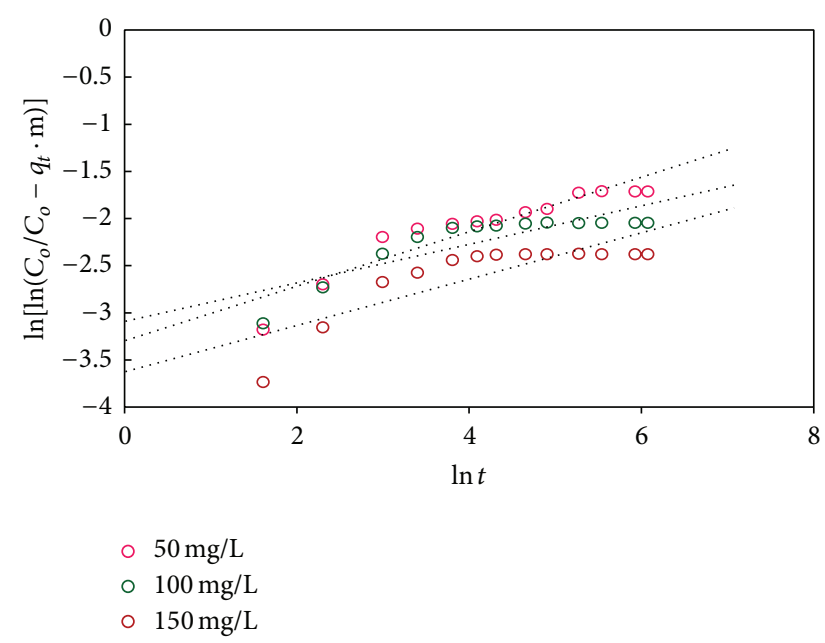

FIGURE 17: Representation of Bangham's plots for MB adsorption on $\mathrm{H}-\mathrm{WH}$ for different initial concentration at $\mathrm{pH}$ of 6.9 and $27 \pm 2^{\circ} \mathrm{C}$.

important to different extents in the removal process. In (15), $\alpha$ and $k_{o}$ are Bangham's constants while $\alpha$ is found to be $0.2891,0.2044$, and 0.2457 , respectively, as the initial methylene blue concentration increases from 50 to $100 \mathrm{mg} / \mathrm{L}$. It can be seen that, with IMBC, the values of $k_{o}$ increase from 0.06816 to $0.0837 \mathrm{~g}$, and with further increase of IMBC, $k_{o}$ values $(0.050 \mathrm{~g})$ show opposite trends. This statement supports the decrease in adsorption capacity with increase in adsorbent mass that is; mainly attributed from the nonsaturation of the adsorption sites of W-HW adsorbents during the adsorption process. Therefore, Bangham's equation cannot explain the $\mathrm{MB}$ adsorption process onto $\mathrm{H}-\mathrm{WH}$ adsorbent sufficiently because the linear regression coefficient values $(0.8635,0.7234$, and 0.6845 , resp., for studied concentration of 50,100 , and $150 \mathrm{mg} / \mathrm{L}$ ) are far away from the unity and this tendency increases with IMBC.

\section{Conclusions}

The present study shows that the $\mathrm{HCl}$ acid treated waterhyacinth $(\mathrm{H}-\mathrm{WH})$ can be used as an adsorbent for the removal of $\mathrm{MB}$ from its aqueous solutions. Upon comparing all the isotherm models, the isotherm results predicted by the Langmuir model coincide with the experimental values with a high correlation coefficient. The equilibrium data fitted very well in a Langmuir isotherm equation, confirming the monolayer sorption of $\mathrm{MB}$ onto $\mathrm{H}-\mathrm{WH}$ with a monolayer sorption capacity of $63.30 \mathrm{mg} / \mathrm{g}$. However, Freundlich, Temkin, and Halsey isotherm model equations were used to express the adsorption phenomenon of $\mathrm{MB}$. The kinetics of $\mathrm{MB}$ adsorption onto $\mathrm{H}-\mathrm{WH}$ was examined using $\mathrm{PFO}$, PSO, IPD, and Bangham's kinetic model. As is evident from the adsorption profiles the PSO equations provide a best fit description for the sorption of $\mathrm{MB}$ onto the $\mathrm{H}-\mathrm{WH}$ adsorbent amongst several kinetic models, due to its high correlation coefficient. The adsorption of $\mathrm{MB}$ via the $\mathrm{H}-\mathrm{WH}$ adsorbent may be controlled by external mass transfer followed by IPD.

\section{Nomenclature}

$q_{e}: \quad$ Adsorption capacity at equilibrium $(\mathrm{mg} / \mathrm{g})$

$q_{t}: \quad$ Adsorption capacity at time $t(\mathrm{mg} / \mathrm{g})$

$R_{w}: \quad$ Approaching equilibrium factor

$\alpha$ and $k_{o}$ : Bangham's constants

$C_{t}: \quad$ Concentration of solution at time $t(\mathrm{mg} / \mathrm{L})$

$n_{G}: \quad$ Cooperative binding constant

$Q_{t}: \quad$ Dimensionless factor

$R_{L}: \quad$ Dimensionless separation factor

$D_{i}: \quad$ Effective diffusion coefficient $\left(\mathrm{m}^{2} / \mathrm{s}\right)$

$\mathrm{C}_{e}: \quad$ Equilibrium $\mathrm{MB}$ concentration $(\mathrm{mg} / \mathrm{L})$

$K_{f}: \quad$ Freundlich constants related to adsorption

n: $\quad$ Freundlich constants related to adsorption

intensity

$K_{G}$ : Generalized isotherm constants (mg/L)

$n_{H}$ : Halsey isotherm constant

$K_{H}: \quad$ Halsey isotherm constant $(\mathrm{L} / \mathrm{g})$

$\mathrm{H}-\mathrm{WH}$ : Hydrochloric acid treated $\mathrm{WH}$

$\mathrm{C}_{0}$ : $\quad$ Initial $\mathrm{MB}$ concentration $(\mathrm{mg} / \mathrm{L})$

IPD: Intraparticle diffusion coefficient

$k_{W M}: \quad$ IPD rate constant $\left(\mathrm{mg} \cdot \mathrm{g}^{-1} \cdot \mathrm{min}^{-1 / 2}\right)$

$K_{L}: \quad$ Langmuir isotherm constants $(\mathrm{L} / \mathrm{mg})$

$W: \quad$ Mass of dry adsorbent (g)

$B_{t}: \quad$ Mathematical function of $F=q_{t} / q_{e}$

$q_{\text {max }}: \quad$ Maximum adsorption capacity $(\mathrm{mg} / \mathrm{g})$

MB: Methylene blue

NSD: Normalized standard deviation

$N$ : Number of data points

$K_{1}$ : $\quad$ PFO rate constant $\left(\mathrm{min}^{-1}\right)$

$\mathrm{pH}_{\mathrm{Pzc}}: \quad \mathrm{pH}$ at the point of zero charge

PFO: Pseudo-first-order kinetic model

PSO: Pseudo-second-order kinetic model

$K_{2}: \quad$ PSO rate constant $\left(\mathrm{g} \cdot \mathrm{mg}^{-1} \cdot \mathrm{min}^{-1}\right)$

$R^{2}$ : $\quad$ Regression coefficient

EABS: Sum of absolute errors

SSE: $\quad$ Sum of the errors squared

$B_{T}$ : Temkin constant related to heat of adsorption

$K_{T}: \quad$ Temkin isotherm constants $(\mathrm{L} / \mathrm{mg})$

$V: \quad$ Volume of solution (L)

WH: Water-hyacinth.

\section{Conflict of Interests}

The authors declare that there is no conflict of interests regarding the publication of this paper.

\section{References}

[1] M. S. Kini, M. Saidutta, and V. R. Murty, "Studies on biosorption of methylene blue from aqueous solutions by powdered palm tree flower (Borassus flabellifer)," International Journal of Chemical Engineering, vol. 2014, Article ID 306519, 13 pages, 2014.

[2] J. K. Nduka, "Application of chemically modified and unmodified waste biological sorbents in treatment of wastewater," 
International Journal of Chemical Engineering, vol. 2012, Article ID 751240, 7 pages, 2012.

[3] P. Janoš, "Sorption of basic dyes onto iron humate," Environmental Science and Technology, vol. 37, no. 24, pp. 5792-5798, 2003.

[4] M. I. El-Khaiary, "Kinetics and mechanism of adsorption of methylene blue from aqueous solution by nitric-acid treated water-hyacinth," Journal of Hazardous Materials, vol. 147, no. 12, pp. 28-36, 2007.

[5] S. H. Hasan, M. Talat, and S. Rai, "Sorption of cadmium and zinc from aqueous solutions by water hyacinth (Eichchornia crassipes)," Bioresource Technology, vol. 98, no. 4, pp. 918-928, 2007.

[6] B. Wolverton, R. McDonald, and J. Gordon, "Water hyacinths and alligator weeds for final filtration of sewage," NASA Technical Memorandum TM-X72724, NASA, Washington, DC, USA, 1976.

[7] M. Ibrahim, R. Mahani, O. Osman, and T. Scheytt, "Effect of physical and chemical treatments on the electrical and structural properties of water hyacinth," The Open Spectroscopy Journal, vol. 4, pp. 32-40, 2010.

[8] A. Malik, "Environmental challenge vis a vis opportunity: the case of water hyacinth," Environment International, vol. 33, no. 1, pp. 122-138, 2007.

[9] M. Uddin, M. Islam, and M. Abedin, "Adsorption of phenol from aqueous solution by water hyacinth ash," ARPN Journal of Engineering and Applied Sciences, vol. 2, no. 2, pp. 11-17, 2007.

[10] R. Gandhimathi, S. Ramesh, V. Arun, and P. Nidheesh, "Biosorption of $\mathrm{Cu}(\mathrm{II})$ and $\mathrm{Zn}$ (II) ions from aqueous solution by water hyacinth (Eichhornia crassipes)," International Journal of Environment and Waste Management, vol. 11, no. 4, pp. 365386, 2013.

[11] K. C. Bhainsa and S. F. D’Souza, “Uranium(VI) biosorption by dried roots of Eichhornia crassipes (water hyacinth)," Journal of Environmental Science and Health A, vol. 36, no. 9, pp. 1621-1631, 2001.

[12] K. S. Low, C. K. Lee, and K. K. Tan, "Biosorption of basic dyes by water hyacinth roots," Bioresource Technology, vol. 52, no. 1 , pp. 79-83, 1995.

[13] S. Kaur, S. Rani, and R. K. Mahajan, "Adsorptive removal of dye crystal violet onto low-cost carbon produced from Eichhornia plant: kinetic, equilibrium, and thermodynamic studies," Desalination and Water Treatment, 2013.

[14] M. Soni, A. K. Sharma, J. K. Srivastava, and J. S. Yadav, "Adsorptive removal of methylene blue dye from an aqueous solution using water hyacinth root powder as a low cost adsorbent," International Journal of Chemical Sciences and Applications, vol. 3, no. 3, pp. 338-345, 2012.

[15] S. M. Kanawade and R. Gaikwad, "Removal of methylene blue from effluent by using activated carbon and water hyacinth as adsorbent," International Journal of Chemical Engineering and Applications, vol. 2, pp. 317-319, 2011.

[16] M. Idrees, A. Adnan, S. Sheikh et al., "Optimization of dilute acid pretreatment of water hyacinth biomass for enzymatic hydrolysis and ethanol production," EXCLI Journal, vol. 12, pp. 30-40, 2013.

[17] P. S. Ganesh, E. V. Ramasamy, S. Gajalakshmi, and S. A. Abbasi, "Extraction of volatile fatty acids (VFAs) from water hyacinth using inexpensive contraptions, and the use of the VFAs as feed supplement in conventional biogas digesters with concomitant final disposal of water hyacinth as vermicompost," Biochemical Engineering Journal, vol. 27, no. 1, pp. 17-23, 2005.
[18] E. Kiefer, L. Sigg, and P. Schosseler, "Chemical and spectroscopic characterization of algae surfaces," Environmental Science \& Technology, vol. 31, no. 3, pp. 759-764, 1997.

[19] I. Langmuir, "The constitution and fundamental properties of solids and liquids. Part I. Solids," The Journal of the American Chemical Society, vol. 38, no. 2, pp. 2221-2295, 1916.

[20] H. Freundlich, "Over the adsorption in solution," Journal of Physical Chemistry, vol. 57, pp. 385-470, 1906.

[21] K. Fytianos, E. Voudrias, and E. Kokkalis, "Sorption-desorption behaviour of 2,4-dichlorophenol by marine sediments," Chemosphere, vol. 40, no. 1, pp. 3-6, 2000.

[22] M. I. Temkin and Pyzhev, "Kinetics of ammonia synthesis on promoted iron catalysts," Acta Physiochimica URSS, vol. 12, pp. 327-356, 1940.

[23] G. Halsey, "Physical adsorption on non-uniform surfaces," The Journal of Chemical Physics, vol. 16, no. 10, pp. 931-937, 1948.

[24] F. Kargi and S. Ozmihci, "Biosorption performance of powdered activated sludge for removal of different dyestuffs," Enzyme and Microbial Technology, vol. 35, no. 2-3, pp. 267-271, 2004.

[25] Y. S. Ho and G. McKay, "Sorption of dye from aqueous solution by peat," Chemical Engineering Journal, vol. 70, no. 2, pp. 115$124,1998$.

[26] V. J. P. Poots, G. McKay, and J. J. Healy, “The removal of acid dye from effluent using natural adsorbents. I. Peat," Water Research, vol. 10, no. 12, pp. 1061-1066, 1976.

[27] N. S. Maurya, A. K. Mittal, P. Cornel, and E. Rother, "Biosorption of dyes using dead macro fungi: effect of dye structure, ionic strength and $\mathrm{pH}$,' Bioresource Technology, vol. 97, no. 3, pp. 512-521, 2006.

[28] X. S. Wang, Y. Zhou, Y. Jiang, and C. Sun, "The removal of basic dyes from aqueous solutions using agricultural by-products," Journal of Hazardous Materials, vol. 157, no. 2-3, pp. 374-385, 2008.

[29] P. K. Malik, "Use of activated carbons prepared from sawdust and rice-husk for adsoprtion of acid dyes: a case study of acid yellow 36," Dyes and Pigments, vol. 56, no. 3, pp. 239-249, 2003.

[30] K. P. Singh, D. Mohan, S. Sinha, G. S. Tondon, and D. Gosh, "Color removal from wastewater using low-cost activated carbon derived from agricultural waste material," Industrial and Engineering Chemistry Research, vol. 42, no. 9, pp. 1965-1976, 2003.

[31] M. N. Uddin, M. T. Islam, M. H. Chakrabarti, and M. S. Islam, "Adsorptive removal of methylene blue from aqueous solutions by means of $\mathrm{HCl}$ treated water hyacinth: isotherms and performance studies," Journal of Purity, Utility Reaction \& Environment, vol. 2, no. 3, pp. 63-84, 2013.

[32] S. Patil, S. Renukdas, and N. Patel, "Removal of methylene blue, a basic dye from aqueous solutions by adsorption using teak tree (Tectona grandis) bark powder," International Journal of Environmental Sciences, vol. 1, no. 5, pp. 711-726, 2011.

[33] R. Han, W. Zou, Z. Zhang, J. Shi, and J. Yang, "Removal of copper(II) and lead(II) from aqueous solution by manganese oxide coated sand. I. Characterization and kinetic study," Journal of Hazardous Materials, vol. 137, no. 1, pp. 384-395, 2006.

[34] J. Bujdák and P. Komadel, "Interaction of methylene blue with reduced charge montmorillonite," The Journal of Physical Chemistry B, vol. 101, no. 44, pp. 9065-9068, 1997.

[35] A. P. P. Cione, M. G. Neumann, and F. Gessner, “Timedependent spectrophotometric study of the interaction of basic dyes with clays: III. Mixed dye aggregates on SWy-1 and Laponite," Journal of Colloid and Interface Science, vol. 198, no. 1, pp. 106-112, 1998. 
[36] A. M. Ben Hamissa, F. Brouers, B. Mahjoub, and M. Seffen, "Adsorption of textile dyes using agave americana (L.) fibres: equilibrium and kinetics modelling," Adsorption Science and Technology, vol. 25, no. 5, pp. 311-325, 2007.

[37] Y. Özdemir, M. Doğan, and M. Alkan, "Adsorption of cationic dyes from aqueous solutions by sepiolite," Microporous and Mesoporous Materials, vol. 96, no. 1-3, pp. 419-427, 2006.

[38] G. Newcombe and M. Drikas, "Adsorption of NOM onto activated carbon: electrostatic and non-electrostatic effects," Carbon, vol. 35, no. 9, pp. 1239-1250, 1997.

[39] G. Alberghina, R. Bianchini, M. Fichera, and S. Fisichella, "Dimerization of Cibacron Blue F3GA and other dyes: influence of salts and temperature," Dyes and Pigments, vol. 46, no. 3, pp. 129-137, 2000.

[40] B. E. Reed and M. R. Matsumoto, "Modeling CD adsorption in single and binary adsorbent (PAC) systems," Journal of Environmental Engineering, vol. 119, no. 2, pp. 332-348, 1993.

[41] F.-C. Wu, R.-L. Tseng, S.-C. Huang, and R.-S. Juang, "Characteristics of pseudo-second-order kinetic model for liquid-phase adsorption: a mini-review," Chemical Engineering Journal, vol. 151, no. 1-3, pp. 1-9, 2009.

[42] V. C. Srivastava, M. M. Swamy, I. D. Mall, B. Prasad, and I. M. Mishra, "Adsorptive removal of phenol by bagasse fly ash and activated carbon: equilibrium, kinetics and thermodynamics," Colloids and Surfaces A: Physicochemical and Engineering Aspects, vol. 272, no. 1-2, pp. 89-104, 2006.

[43] Z. Yaneva and B. Koumanova, "Comparative modelling of mono- and dinitrophenols sorption on yellow bentonite from aqueous solutions," Journal of Colloid and Interface Science, vol. 293, no. 2, pp. 303-311, 2006.

[44] W. Weber and J. Morris, "Kinetics of adsorption on carbon from solution," Journal of Sanitary Engineering Division, vol. 89, pp. 31-60, 1963.

[45] C. Aharoni, S. Sideman, and E. Hoffer, "Adsorption of phosphate ions by collodion-coated alumina," Journal of Chemical Technology and Biotechnology, vol. 29, pp. 404-412, 1979.

[46] E. Tütem, R. Apak, and Ç. F. Ünal, "Adsorptive removal of chlorophenols from water by bituminous shale," Water Research, vol. 32, no. 8, pp. 2315-2324, 1998. 

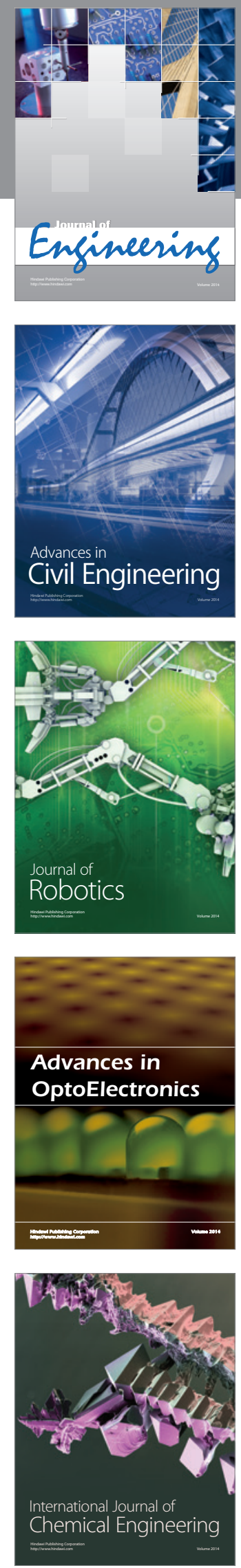

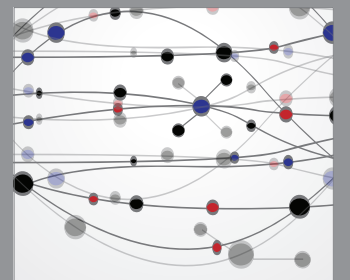

The Scientific World Journal
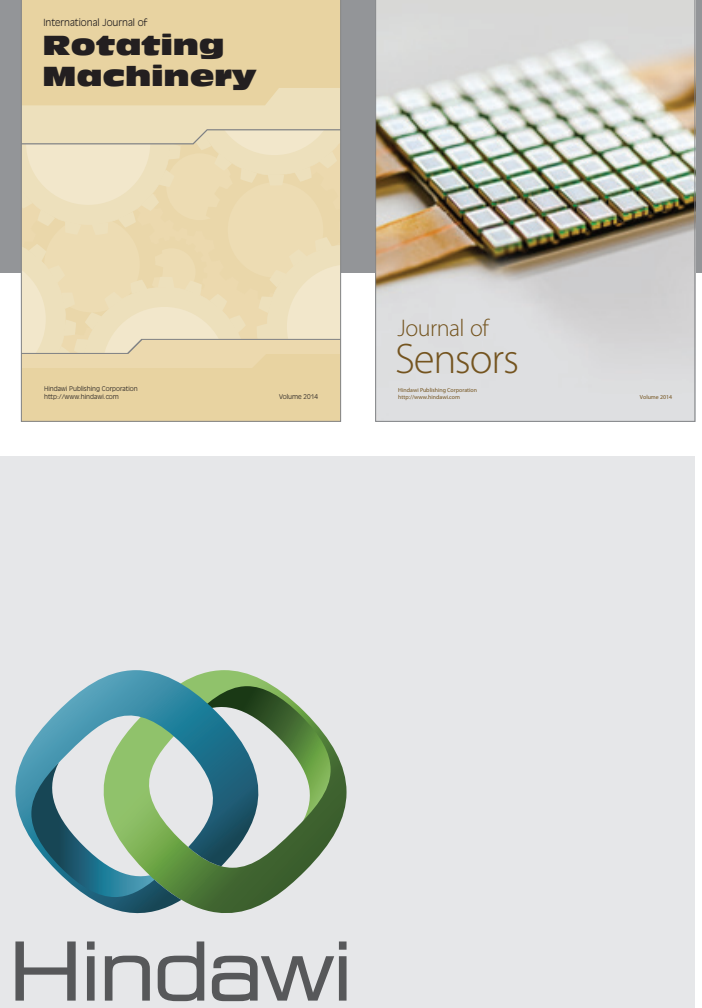

Submit your manuscripts at http://www.hindawi.com
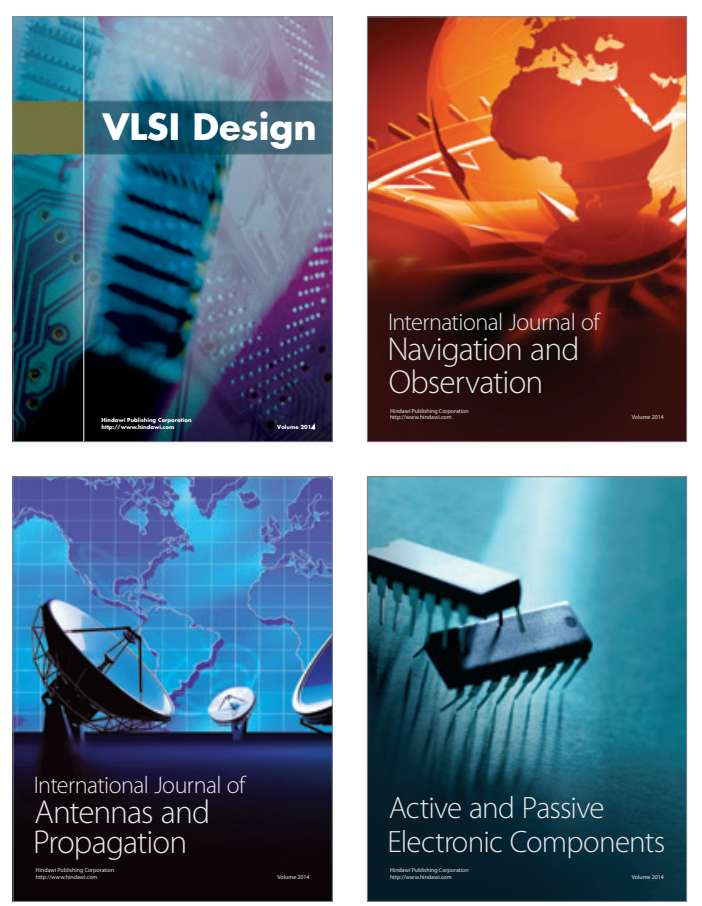
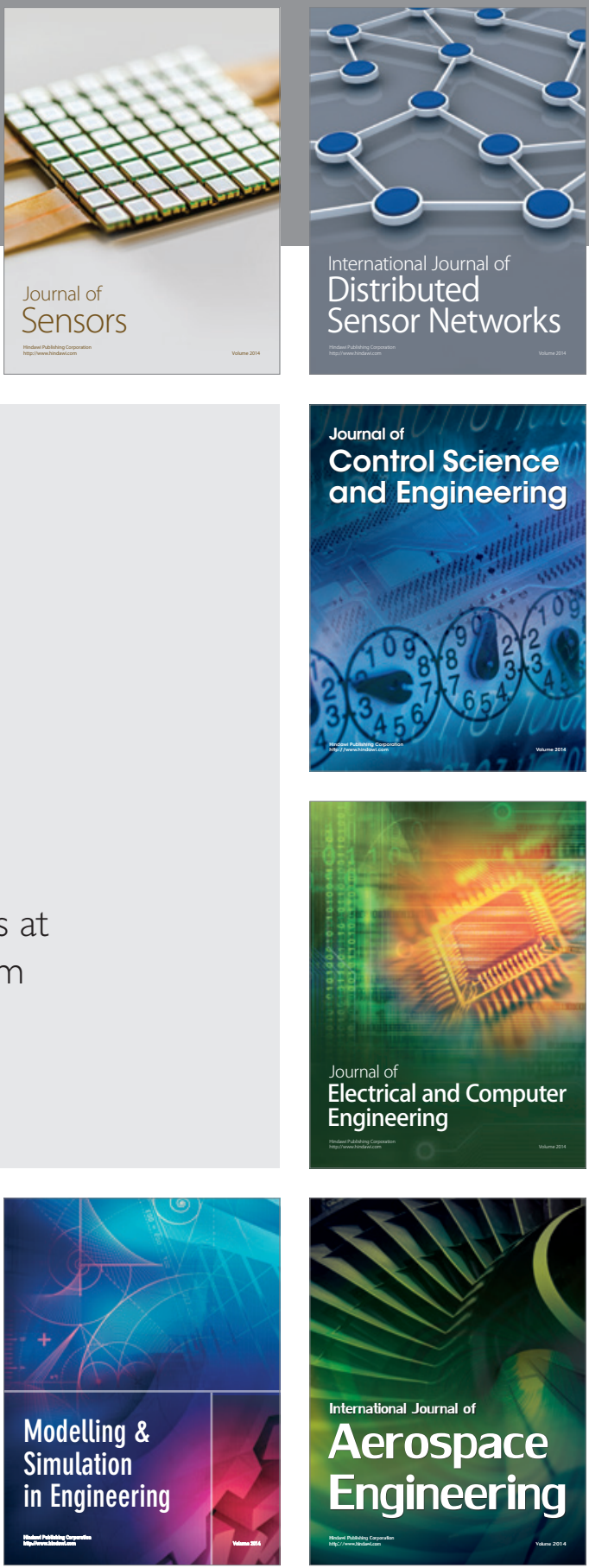

Journal of

Control Science

and Engineering
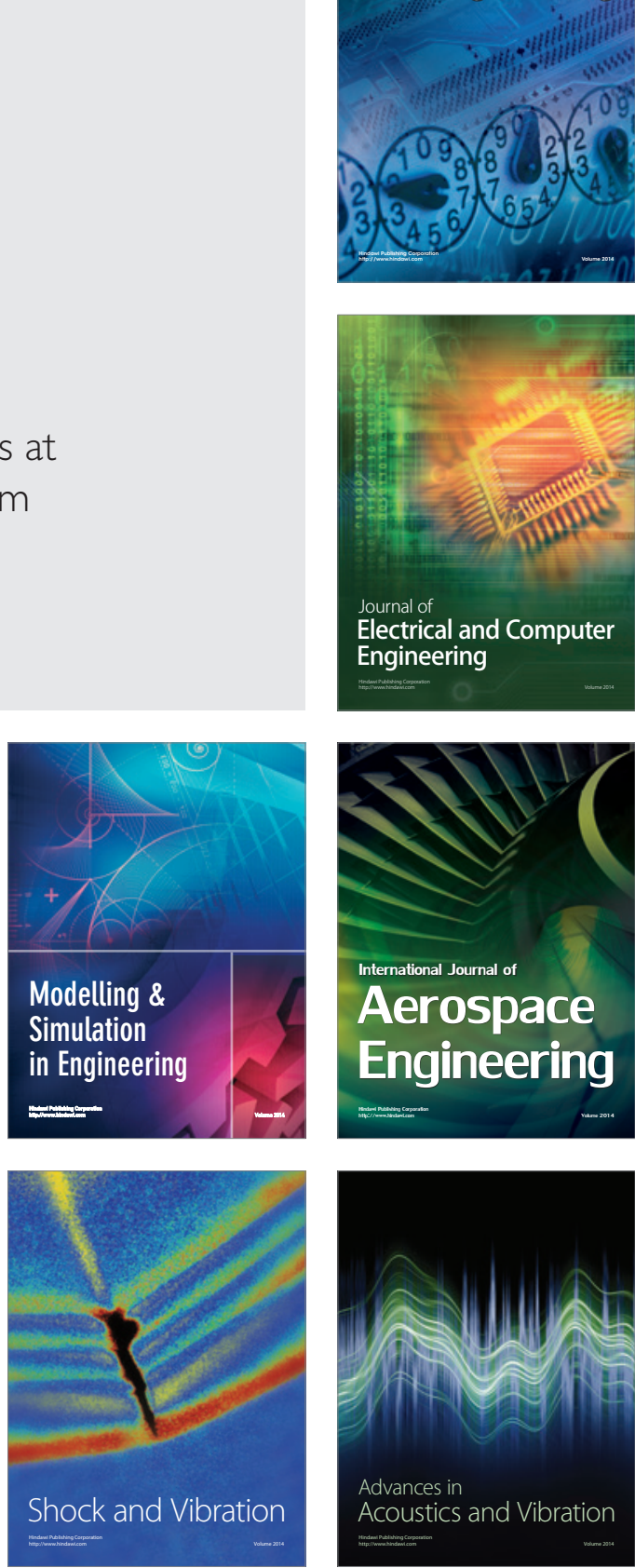